\title{
Molecular Dynamics of a Presynaptic Active Zone Protein Studied in Munc13-1-Enhanced Yellow Fluorescent Protein Knock-In Mutant Mice
}

\author{
Stefan Kalla, ${ }^{1}$ Michal Stern, ${ }^{3}$ Jayeeta Basu, ${ }_{4}^{4}$ Frederique Varoqueaux, ${ }^{1}$ Kerstin Reim, ${ }^{1}$ Christian Rosenmund, ${ }^{4}$ \\ Noam E. Ziv, ${ }^{3}$ and Nils Brose ${ }^{1,2}$ \\ ${ }^{1}$ Department of Molecular Neurobiology, ${ }^{2}$ Deutsche Forschungsgemeinschaft Research Center for Molecular Physiology of the Brain, Max-Planck-Institute \\ of Experimental Medicine, D-37075 Göttingen, Germany, ${ }^{3}$ Department of Physiology and Rappaport Family Institute for Research in the Medical Sciences, \\ Technion Faculty of Medicine, Haifa 31096, Israel, and ${ }^{4}$ Department of Molecular and Human Genetics and Department of Neuroscience, Baylor College of \\ Medicine, Houston, Texas 77030
}

GFP (green fluorescent protein) fusion proteins have revolutionized research on protein dynamics at synapses. However, corresponding analyses usually involve protein expression methods that override endogenous regulatory mechanisms, and therefore cause overexpression and temporal or spatial misexpression of exogenous fusion proteins, which may seriously compromise the physiological validity of such experiments. These problems can be circumvented by using knock-in mutagenesis of the endogenous genomic locus to tag the protein of interest with a fluorescent protein. We generated knock-in mice expressing a fusion protein of the presynaptic active zone protein Munc13-1 and enhanced yellow fluorescent protein (EYFP) from the Munc13-1 locus. Munc13-1-EYFP-containing nerve cells and synapses are functionally identical to those of wild-type mice. However, their presynaptic active zones are distinctly fluorescent and readily amenable for imaging. We demonstrated the usefulness of these mice by studying the molecular dynamics of Munc13-1-EYFP at individual presynaptic sites. Fluorescence recovery after photobleaching (FRAP) experiments revealed that Munc13-1-EYFP is rapidly and continuously lost from and incorporated into active zones $\left(\tau_{1} \sim 3 \mathrm{~min} ; \tau_{2} \sim 80 \mathrm{~min}\right)$. Munc13-1-EYFP steady-state levels and exchange kinetics were not affected by proteasome inhibitors or acute synaptic stimulation, but exchange kinetics were reduced by chronic suppression of spontaneous activity. These experiments, performed in a minimally perturbed system, provide evidence that presynaptic active zones of mammalian CNS synapses are highly dynamic structures. They demonstrate the usefulness of the knock-in approach in general and of Munc13-1-EYFP knock-in mice in particular for imaging synaptic protein dynamics.

Key words: CAZ; live imaging; priming; synapse; protein turnover; protein degradation

\section{Introduction}

Neurotransmitter release at fast chemical synapses is restricted to active zones, where synaptic vesicle docking, priming, and exocytosis take place in a highly coordinated manner. These processes are orchestrated by specific active zone cytomatrix (CAZ) proteins that include ELKSs (glutamine, leucine, lysine, and serine-rich proteins), $\alpha$-Rab3a-interacting molecules ( $\alpha$ RIMs), Piccolo/Aczonin, Bassoon, $\alpha$-Liprins, or Munc13s (Dresbach et al., 2001; Rosenmund et al., 2003; Südhof, 2004; Zhai and Bellen,

Received 0ct. 4, 2006; revised Nov. 9, 2006; accepted Nov. 9, 2006.

This work was supported by grants from the Deutsche Forschungsgemeinschaft (SFB406/A1, GRK632, and FZT103) (N.B.) and the German-Israeli Foundation for Scientific Research and Development (GIF I-840-194.1/2004) (N.E.Z., N.B.). We thank F. Benseler, I. Thanhäuser, D. Schwerdtfeger (Göttingen, Germany), and H. Deng (Houston, TX) for excellent technical assistance and the staff of the animal facility at the Max-Planck-Institute of Experimental Medicine (Göttingen, Germany) for blastocyst injections and maintenance of mouse colonies.

Correspondence should be addressed to either of the following: Nils Brose, Department of Molecular Neurobiology, Max-Planck-Institute of Experimental Medicine, Hermann-Rein-Strasse 3, D-37075 Göttingen, Germany, Email: brose@em.mpg.de; or Noam Ziv, Department of Physiology and Rappaport Family Institute for Research in the Medical Sciences, Technion Faculty of Medicine, P.0. Box 9649 Bat Galim, Haifa 31096, Israel, E-mail: noamz@netvision.net.il.

D01:10.1523/JNEUROSCI.4330-06.2006

Copyright $\odot 2006$ Society for Neuroscience $\quad$ 0270-6474/06/2613054-13\$15.00/0
2004; Zhen and Jin, 2004). The introduction of green fluorescent protein (GFP) (Chalfie et al., 1994; Feng et al., 2000; Miyawaki et al., 2003) has contributed enormously to the analysis of CAZ protein trafficking and active zone formation (Dresbach et al., 2003, 2006; Shapira et al., 2003; Bresler et al., 2004; Tsuriel et al., 2006) and has revolutionized our understanding of presynapse function.

Use of GFP fusion proteins in these and most related experiments relied on vector- or virus-mediated expression, which bears two caveats. First, because strong heterologous promoters are typically used, the temporal expression patterns of GFP fusion proteins do not reflect those of endogenous proteins. Second, GFP fusion proteins are expressed in excess of their endogenous counterparts, and consequently often exhibit aberrant subcellular localization, trafficking, or stability.

Viruses that express proteins less strongly can solve the overexpression problem but still cause temporal misexpression. This is partially solved by bacterial artificial chromosome (BAC) transgenesis strategies in which endogenous promoters are used for GFP fusion protein expression (Gong et al., 2003). However, even advanced BAC transgenesis strategies can cause problems. 
First, transgenic mice usually carry multiple transgene copies, leading to overexpression. Second, transgenes can interfere with unrelated genes at the insertion site. Third, transgenes must contain the entire transcription unit including all regulatory elements, whose locations are hard to predict. This is particularly relevant for large genes in which the BAC size becomes a limiting factor (Gong et al., 2003).

An alternative solution to the misexpression and overexpression problems mentioned above is to tag the protein of interest by a knock-in (KI) mutation of the endogenous gene. This approach, however, has rarely been pursued because reporter expression levels were expected to be insufficient for fluorescence imaging (Gong et al., 2003). In practically all published cases, the fluorescence of GFP fusion proteins was used to identify neurons or image their overall architecture (Tamamaki et al., 2003). Whether smaller subcellular structures could be imaged was not tested systematically.

We generated and characterized KI mice expressing a Munc13-1-enhanced yellow fluorescent protein (EYFP) fusion protein instead of wild-type (WT) Munc13-1 from the Munc13-1 gene to study molecular dynamics at active zones. We focused on Munc13-1 because it is expressed in all brain neurons, specifically localized to active zones (Betz et al., 1998; Rhee et al., 2002), essential for active zone function (Augustin et al., 1999b; Varoqueaux et al., 2002), and not affected by C-terminal GFP fusion (Betz et al., 2001; Rhee et al., 2002; Rosenmund et al., 2002; Junge et al., 2004). The feasibility and usefulness of our KI approach for imaging synaptic protein dynamics in a minimally perturbed system are demonstrated in the experiments described below.

\section{Materials and Methods}

Generation of Munc13-1-EYFP KIs. The targeting vector for the generation of Munc13-1-EYFP KIs was constructed on the basis of a $15 \mathrm{~kb}$ genomic clone in pBluescript (pM13-1-3'), which had been isolated from a $\lambda$ FIXII genomic library of the SV129 mouse strain (Stratagene, La Jolla, CA). In the targeting vector, the STOP codon in the last coding exon (exon 45) of the Munc13-1 gene was replaced in-frame by an EYFP cDNA fragment from pEYFP-N1 (Clontech, Cambridge, UK) using PCR with engineered primers and subcloning. A neomycin resistance cassette flanked by two loxP sites was inserted in sense orientation $3^{\prime}$ of the EYFP STOP codon, again using PCR with engineered primers and subcloning. By using conventional cloning strategies, the EYFP-loxP-Neo-loxP cassette was inserted between a $3.2 \mathrm{~kb}$ genomic sequence in $3^{\prime}$ direction and a $4.6 \mathrm{~kb}$ genomic sequence in $5^{\prime}$ direction, and two copies of the HSV (herpes simplex virus) thymidine kinase gene were attached at the $5^{\prime}$ end of the targeting vector (see Fig. $1 A$ ). Mice carrying the mutated Munc131-EYFP-Neo gene $\left(\mathrm{m}_{\mathrm{n}} /+\right)$ were generated by homologous recombination in embryonic stem cells (SV129/ola) as described previously (Thomas and Capecchi, 1987; Augustin et al., 1999b) and identified by Southern blotting (see Fig. 1B) or PCR. To eliminate deleterious effects of the neomycin resistance gene, we crossed heterozygous mice carrying the mutated Munc13-1-EYFP-Neo gene $\left(\mathrm{m}_{\mathrm{n}} /+\right)$ with EIIa-cre mice, which carry the cre transgene under the control of the adenovirus EIIa promoter and express Cre recombinase in early embryonic stages (Lakso et al., 1996). Successfully recombined Munc13-1-EYFP genes $(\mathrm{m} /+)$ in offspring from these interbreedings were genotyped by Southern blotting (see Fig. $1 B$ ) or PCR. Except for initial comparative analysis of mice carrying Munc13-1-EYFP-Neo or Munc13-1-EYFP genes (see Fig. 1C), mice homozygous $(\mathrm{m} / \mathrm{m})$ or heterozygous $(\mathrm{m} /+)$ for the Cre recombined Munc13-1-EYFP gene were used for all experiments. For biochemical and morphological experiments (see Figs. 2, 3), WT, m/+, and m/m littermates were used. For electrophysiological experiments, neurons from $\mathrm{m} / \mathrm{m}$ mice were compared with neurons from a mouse line with the same SV129/C57BL/6 mosaic genetic background.

RNase protection assay and biochemical analyses. Total RNA from adult $\mathrm{WT}$ and $\mathrm{m} / \mathrm{m}$ mouse brains was prepared with Trizol reagent (Invitro- gen, San Diego, CA), and Munc13-1 mRNA levels were quantified by RNase protection assay using the RPA III kit (Ambion, Austin, TX) in combination with chemiluminescence detection (Pierce, Rockford, IL) and ImageJ (http://rsb.info.nih.gov/ij). A rat Munc13-1 cDNA fragment representing bp 5988-6313 of the published coding sequence (GenBank accession number U24070) was used as probe. RNA levels were normalized to Cyclophilin mRNA levels and are expressed as mean \pm SD. SDSPAGE and Western blotting were performed according to standard procedures using HRP-coupled goat anti-rabbit or HRP-coupled goat antimouse (Bio-Rad, Hercules, CA) secondary antibodies. Goat anti-rabbit or goat anti-mouse secondary antibodies coupled to Odyssey IRDye 680 or Odyssey IRDye 800 (Rockland Immunochemicals, Gilbertsville, PA) were used for quantitative Western blotting using the Odyssey system (LI-COR, Lincoln, NE). Signals on Western blots were either visualized by enhanced chemiluminescence (Amersham Biosciences, Piscataway, $\mathrm{NJ}$ ) and quantified with ImageJ (http://rsb.info.nih.gov/ij) or analyzed with the Odyssey imaging system (LI-COR). The two assay procedures yielded very similar results. Quantitative data are expressed as mean \pm SD. Subcellular fractionations were prepared essentially as described previously (Jones and Matus, 1974). They were designated as follows: Hom, homogenate; P1, nuclear pellet; P2, crude synaptosomal pellet; P3, light membrane pellet; LP1, lysed synaptosomal membranes; LP2, crude synaptic vesicle fraction; SPM, synaptic plasma membranes; S1, supernatant after synaptosome sedimentation; S3, cytosolic fraction; LS1, supernatant after LP1 sedimentation; LS2, cytosolic synaptosomal fraction. For the separation of soluble and particulate material from mouse cortex, individual cortices were homogenized by Ultra-Turrax (IKA, Staufen, Germany), and soluble and particulate fractions were separated by ultracentrifugation $\left(300,000 \times g ; 20 \mathrm{~min} ; 4^{\circ} \mathrm{C}\right)$. The following primary antibodies were used for Western blotting: polyclonal rabbit anti-Munc13-1 (Rhee et al., 2002), monoclonal mouse anti-NMDA receptor 1 (NMDAR1) (Synaptic Systems, Göttingen, Germany), monoclonal mouse anti- $\alpha$ RIM1/2 (BD Transduction Labs, San Diego, CA), monoclonal mouse anti-synaptophysin 1 (Synaptic Systems), and monoclonal anti- $\beta$-tubulin (Sigma, St. Louis, MO).

Immunohistochemistry and immunocytochemistry. For direct Munc131-EYFP fluorescence analyses, $50 \mu \mathrm{m}$ vibratome sections were cut from perfusion fixed (4\% paraformaldehyde) $\mathrm{m} / \mathrm{m}$ and WT mouse brains and observed with a conventional epifluorescence Olympus (Tokyo, Japan) BX61 microscope coupled to an F-ViewII digital camera and AnalySIS image acquisition software (Olympus). For double labeling experiments, mice were perfused with a solution containing $\mathrm{NaCl}(0.9 \%)$ and $\mathrm{NaNO}_{2}$ $(1 \%)$, and their brains were frozen in isopentane at $-40^{\circ} \mathrm{C}$ before storage at $-80^{\circ} \mathrm{C}$. Frozen brains were sectioned on a cryostat, and $14 \mathrm{~mm}$ sections were fixed with methanol and stained with a mouse monoclonal anti-Bassoon antibody (Stessgen, Victoria, British Columbia, Canada) and an Alexa Fluor 633-coupled goat anti-mouse secondary antibody (Invitrogen). Alexa Fluor 633-labeled Bassoon and direct fluorescence of Munc13-1-EYFP were observed with a Leica (Nussloch, Germany) TCS SP2 confocal laser-scanning microscope and corresponding software (Leica). For immunocytochemistry on cultured neurons, cells were fixed in a solution consisting of $4 \%$ formaldehyde and $120 \mathrm{~mm}$ sucrose in PBS for $20 \mathrm{~min}$. The cells were then permeabilized for $10 \mathrm{~min}$ in fixative solution containing $0.25 \%$ Triton X-100 (Sigma). The cells were washed three times in PBS, incubated in 10\% bovine serum albumin (BSA) for $1 \mathrm{~h}$ at $37^{\circ} \mathrm{C}$, and incubated overnight at $4^{\circ} \mathrm{C}$ or for $1 \mathrm{~h}$ at room temperature with primary antibodies in PBS and 1\% BSA. The cells were then rinsed three times for $5 \mathrm{~min}$ with PBS, and incubated in the dark for $1 \mathrm{~h}$ at room temperature with secondary antibodies in PBS and 1\% BSA. The cells were rinsed again with PBS, mounted, and imaged immediately. Primary antibodies used here included rabbit polyclonal anti-Piccolo [kind gift from Dr. Wilko Altrock (Leibniz Institute for Neurobiology, Magdeburg, Germany)], rabbit polyclonal anti-vesicular inhibitory amino acid transporter (VIAAT), guinea pig polyclonal anti-vesicular glutamate transporter 1 (VGluT1) (Chemicon, Temecula, CA), mouse monoclonal anti-postsynaptic density-95 (PSD-95) (clone K28/43; Upstate Biotechnology, Lake Placid, NY), rabbit polyclonal anti-glutamate receptor 1 (GluR1) (Chemicon), and rabbit polyclonal anti-proline-rich synapse-associated protein 2 (ProSAP2) (Bresler et al., 2004). Secondary 
antibodies used were Alexa Fluor 633 goat anti-mouse IgG and IgG2a (Invitrogen), Cy5 AffiniPure donkey anti-guinea pig IgG, anti-mouse IgG, and anti-rabbit IgG (Jackson ImmunoResearch Laboratories, West Grove, PA).

Cell culture and electrophysiology. Autaptic microisland cultures were prepared as described previously (Augustin et al., 1999b) and examined according to previously published protocols (Rhee et al., 2002) at 12-16 $\mathrm{d}$ in vitro (DIV). Electrophysiological data are expressed as mean \pm SEM and significance was determined using Student's $t$ test. Hippocampal and cortical cell cultures for imaging experiments were prepared as described previously (Bresler et al., 2004).

Microscopy. All cell culture experiments were performed using a custom-designed confocal laser-scanning microscope based on a Zeiss (Oberkochen, Germany) Aviovert 200 using a 40×, 1.3 numerical aperture Fluar objective. The system is controlled by software written by one of us (N. E. Ziv) and includes provisions for automated, multisite timelapse microscopy. EYFP was excited using the $514 \mathrm{~nm}$ line of an argon laser and its emission read using a $530-560 \mathrm{~nm}$ bandpass filter (Chroma, Rockingham, VT). N-(3-Triethylammoniumpropyl)-4-( $p$-dibutylaminostyryl)pyridinium dibromide (FM4-64) was excited at $514 \mathrm{~nm}$ wavelength, and its fluorescence emission was read using a $640 \mathrm{~nm}$ long-pass filter. Antibodies conjugated with Cy5/Alexa 633 were excited using the $632 \mathrm{~nm}$ line of a helium neon laser and read using a $640 \mathrm{~nm}$ bandpass filter. Differential interference contrast (DIC) images were acquired by collecting the transmitted laser light with a photomultiplier placed at the end of the DIC optical train of the microscope. For long-term live imaging experiments (e.g., see Fig. 6), coverslips with cells were mounted in a modified version of a commercial chamber (Warner Instruments, Hamden, CT). The chamber was mounted on the microscope stage, and placed within an enclosure flooded with a $0.22-\mu \mathrm{m}$-filtered gas mixture of $5 \% \mathrm{CO}_{2}, 95 \%$ air (controlled by separate flow meters). The chamber and objective were heated to $37-38^{\circ} \mathrm{C}$ using resistors and thermal foil resulting in stable intrachamber temperatures of $33-35^{\circ} \mathrm{C}$. To block proteasome-mediated protein degradation, benzyloxycarbonyl-leucylleucyl-leucinal (MG132) (Calbiochem, La Jolla, CA) was added to the extracellular medium from a stock solution in DMSO $(10 \mathrm{mM})$ to reach a final concentration of $20 \mu \mathrm{M}$. For fluorescence recovery after photobleaching (FRAP) experiments, cells were perfused slowly with preheated Tyrode's saline solution ( $119 \mathrm{~mm} \mathrm{NaCl}, 2.5 \mathrm{~mm} \mathrm{KCl}, 2 \mathrm{~mm} \mathrm{CaCl}_{2}, 2 \mathrm{~mm}$ $\mathrm{MgCl}_{2}, 25 \mathrm{~mm}$ HEPES, $30 \mathrm{~mm}$ glucose, buffered to $\mathrm{pH}$ 7.4) to which 6-cyano-7-nitroquinoxaline-2,3-dione (CNQX) (10 $\mu \mathrm{M})$ and 2-amino5 -phosphonopentanoic acid (AP-5) $(50 \mu \mathrm{M})$ were added. Time-lapse recordings were usually performed by averaging six frames collected at a resolution of $640 \times 480$ pixels, at 12 bits/pixel. Because of the relative sensitivity of EYFP to photobleaching, data were collected at a simple focal plane with the confocal aperture fully open. Focal drift during experiments was corrected automatically before collecting each image using the "autofocus" feature of the microscope (Bresler et al., 2004). Functional presynaptic boutons were visualized by loading them with FM4-64 (Invitrogen). Cells were exposed to FM4-64 by flooding the perfusion chamber with Tyrode's saline solution containing $15 \mu \mathrm{M}$ FM4-64. The neurons were then stimulated to fire action potentials by passing current pulses of $1 \mathrm{~ms}$ and $18 \mathrm{~mA}$ through platinum electrodes placed on both sides of the chamber. The cells were stimulated for $60 \mathrm{~s}$ at $10 \mathrm{~Hz}$, left in the dye for an additional $30 \mathrm{~s}$, and then washed for $8 \mathrm{~min}$ with Tyrode's solution alone. Dye unloading was performed by stimulating the neurons for $120 \mathrm{~s}$ at $10 \mathrm{~Hz}$.

Fluorescence recovery after photobleaching. After the collection of baseline images, photobleaching was performed by scanning two to four preselected $12 \times 12$ pixel $(\sim 2 \times 2 \mu \mathrm{m})$ regions of interest sequentially and repeatedly at $514 \mathrm{~nm}$ at high illumination intensity using the confocal microscope system AOTF until fluorescence was reduced to $40 \%$ of original fluorescence. This procedure was performed programmatically using Visual Basic for applications from within Microsoft Excel to control the microscope system via OLE automation. After the photobleaching procedure, fluorescence recovery was recorded by automated timelapse microscopy.

Imaging data analysis. All data analysis was performed using software (“OpenView") written by one of us (N. E. Ziv). Intensities of fluorescent puncta (Munc13-1-EYFP or secondary antibody fluorescence) were measured by centering $8 \times 8$ to $10 \times 10$ pixel boxes on them, and obtaining the mean pixel value in this rectangular region. For images obtained in FRAP experiments, all data were corrected for ongoing photobleaching according to the following equation:

$$
F_{\text {cor }_{t}}=\frac{F_{t}}{F_{o}} / \frac{F_{\mathrm{nb}_{t}}}{F_{\mathrm{nb}_{o}}},
$$

where $F_{t}$ is the fluorescence at time $t, F_{0}$ is the pre-photobleaching fluorescence, $F_{\mathrm{nb}_{t}}$ is the average fluorescence intensity of 10 nonbleached puncta at time $t$, and $F_{\mathrm{nb}_{t}}$ is the average fluorescence intensity of the same nonbleached puncta at time $t=0$. Best fits of FRAP recovery curves were made according to the following equation:

$$
F_{t}=P_{\mathrm{f}}\left[1-\left(1-F_{\mathrm{bl}}\right) e^{-t / \tau_{\mathrm{f}}}\right]+\left(1-P_{\mathrm{f}}\right)\left[1-\left(1-F_{\mathrm{bl}}\right) e^{-t / \tau_{\mathrm{s}}}\right],
$$

where $P_{\mathrm{f}}$ is the fractional size of the fast pool, $F_{\mathrm{bl}}$ is the normalized fluorescence immediately after the photobleaching procedure, and $\tau_{\mathrm{f}}$ and $\tau_{\mathrm{s}}$ are the recovery time constants for the fast and slow pools, respectively. A program was written in Visual Basic for applications within Microsoft Excel that explored systematically a wide range of $P_{\mathrm{f}}, \tau_{\mathrm{f}}$, and $\tau_{\mathrm{s}}$ combinations, and obtained the values that gave the best fit to the experimental data (minimal sum of squared residuals). Images for figures were processed by linear contrast enhancement and low-pass filtering using Adobe Photoshop and prepared for presentation using Microsoft PowerPoint.

\section{Results}

\section{Basic characterization of Munc13-1-EYFP KIs}

Homozygous Munc13-1-EYFP KIs carrying an EYFP cDNA instead of the stop codon in exon 45 of the Munc13-1 gene, followed by a neomycin resistance cassette in the $3^{\prime}$ untranslated region $\left(\mathrm{m}_{\mathrm{n}} / \mathrm{m}_{\mathrm{n}}\right)$ were generated by homologous recombination in embryonic stem cells and breeding as described in Materials and Methods (Fig. 1A) (Rhee et al., 2002). To eliminate possible deleterious effects of the neomycin resistance cassette, $\mathrm{m}_{\mathrm{n}} /+$ mice were crossed with EIIa-cre mice, which carry the cre transgene under the control of the adenovirus EIIa promoter and express Cre recombinase in early embryonic stages (Lakso et al., 1996). Mice carrying Cre recombined Munc13-1-EYFP genes were bred to yield homozygous Munc13-1-EYFP KIs lacking the neomycin resistance cassette $(\mathrm{m} / \mathrm{m})$ (Fig. $1 A)$. The respective genotypes were initially detected by Southern blotting (Fig. $1 B$ ) and for routine breeding by PCR (Fig. $1 A$ ).

Neither $\mathrm{m}_{\mathrm{n}} / \mathrm{m}_{\mathrm{n}}$ mice nor $\mathrm{m} / \mathrm{m}$ mice showed any obvious behavioral or morphological aberrations. Mice from both lines were viable, had a normal life expectancy, and were fertile. This is in striking contrast to Munc13-1 knock-out (KO) mice (Augustin et al., 1999b) and KIs expressing a diacylglycerol binding deficient Munc13-1 ${ }^{\mathrm{H} 567 \mathrm{~K} / \mathrm{H} 567 \mathrm{~K}}$ variant (Rhee et al., 2002), which die immediately after birth, and provides a first indication that the EYFP tag does not interfere with Munc13-1 function in $\mathrm{m}_{\mathrm{n}} / \mathrm{m}_{\mathrm{n}}$ and $\mathrm{m} / \mathrm{m}$ mice.

\section{Munc13-1-EYFP mRNA and protein expression in Munc13-1-EYFP KIs}

To study the expression of Munc13-1-EYFP mRNA and the expression, developmental regulation, and subcellular distribution of Munc13-1-EYFP protein in mutant mice, we performed RNase protection assays and Western blot analyses on WT, $\mathrm{m} /+$, and $\mathrm{m} / \mathrm{m}$ mouse brains. Analyses of protein expression in whole brains of heterozygous $\mathrm{m}_{\mathrm{n}} /+$ and $\mathrm{m} /+$ mice showed reduced expression levels of Munc13-1-EYFP compared with Munc13-1 (Fig. 1C). Neither in $\mathrm{m}_{\mathrm{n}} /+$ mice nor in $\mathrm{m} /+, \mathrm{m}_{\mathrm{n}} / \mathrm{m}_{\mathrm{n}}$, or $\mathrm{m} / \mathrm{m}$ mice were any truncated Munc13-1-EYFP observed (data not 
A
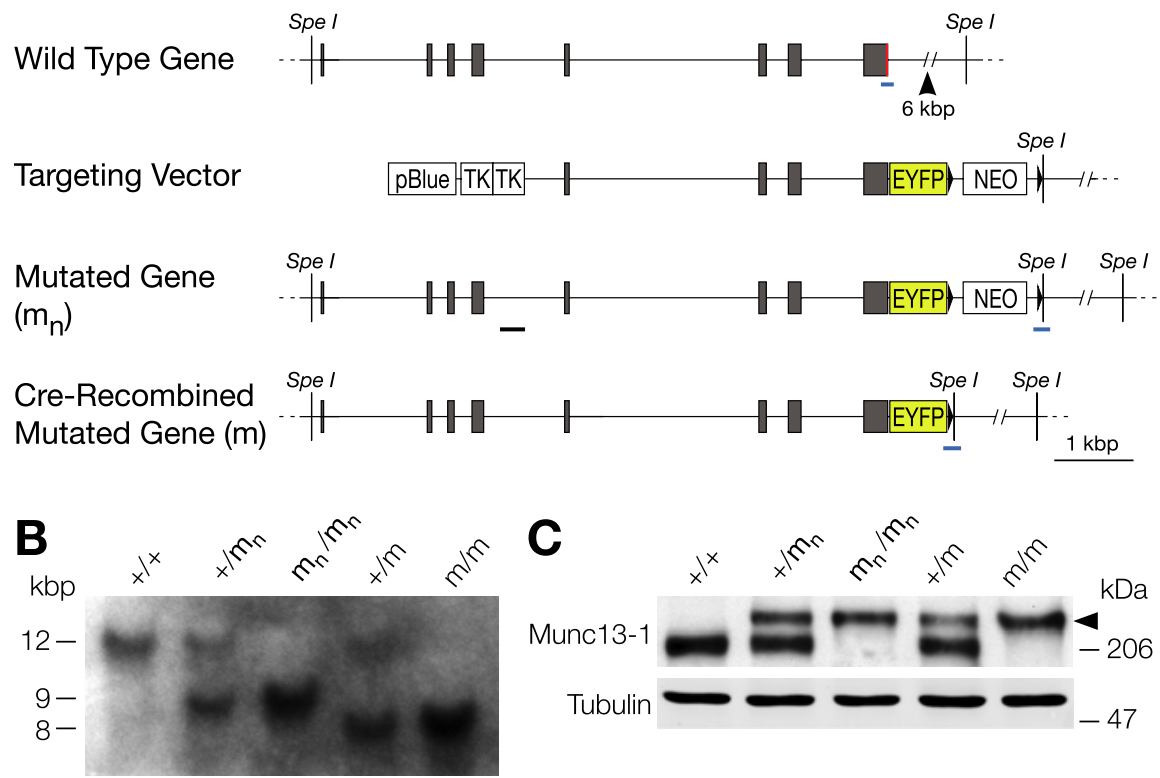

Figure 1. Generation of Munc13-1-EYFP KIs. A, Strategy for the generation of the Munc13-1-EYFP KI mutation in mouse embryonic stem cells. WT Munc13-1 gene, targeting vector, mutated gene after homologous recombination $\left(\mathrm{m}_{\mathrm{n}}\right)$, and mutated gene after $C$ re recombination $(\mathrm{m})$. Exons are indicated by gray boxes. The black triangles indicate loxP sites. A black horizontal bar indicates the probe used for Southern analysis (Spel-digested tail DNA) of mutated genes in mice. PCR products used for genotyping are indicated by the horizontal blue bars. A 6 kbp section of genomic sequence is not shown here and is indicated by an arrowhead in the top panel. NE0, Neomycin resistance gene; pBlue, pBluescript KS; TK, herpes simplex virus thymidine kinase. $\boldsymbol{B}$, Southern blot analysis of mutated genes using Spel-digested mouse tail DNA and the probe indicated in $A . m_{n}$, Mutated gene with neomycin resistance cassette $(9.2 \mathrm{kbp}) ; \mathrm{m}$, mutated gene after (re recombination (8.0 kbp); +/+, WT gene (13.9 kbp). $\boldsymbol{C}$ Western blot analysis of brain homogenates from WT $(+/+)$ mice and mice carrying the mutated gene with neomycin resistance cassette $\left(m_{n}\right)$ or the mutated gene after Cre recombination ( $m$ ). Note that Munc13-1-EYFP protein expression (arrowhead) is reduced in heterozygous mutant mice $\left(m_{n} /+, m /+\right)$ but not in homozygous mutant mice $\left(m_{n} / m_{n}, m / m\right)(F i g .2)$.

shown). For all subsequent experiments, $\mathrm{m} /+$ and $\mathrm{m} / \mathrm{m}$ mice carrying Cre recombined Munc13-1-EYFP genes were used.

To compare the expression profiles and biochemical characteristics of Munc13-1-EYFP and Munc13-1, we studied heterozygous $\mathrm{m} /+$ mice, which coexpress Munc13-1-EYFP and Munc13-1. In a first set of experiments, we determined brain protein expression levels at different developmental stages [embryonic day 18 (E18) to postnatal day 90 (P90)]. In concordance with previous observations (Brose et al., 1995; Betz et al., 1997; Augustin et al., 1999a), the expression levels of both Munc13-1EYFP and Munc13-1 were very low at birth and increased exactly in parallel during postnatal development to reach a plateau at P12-P15 (Fig. 2A). This developmental expression profile is similar to that of other synaptic markers such as $\alpha \mathrm{RIM} 1 / 2$, NMDAR1, and synaptophysin 1 (Fig. 2A).

In subsequent experiments, we compared the distribution of Munc13-1-EYFP and Munc13-1 in various subcellular fractions from $\mathrm{m} /+$ brains. The subcellular fractionation profiles of Munc13-1-EYFP and Munc13-1 were identical. In agreement with previous studies (Brose et al., 1995; Betz et al., 1997; Augustin et al., 1999a), both proteins were enriched in synaptic plasma membranes (SPMs), as was the case for the active zone markers $\alpha$ RIM1/2 and the postsynaptic density component NMDAR 1 (Fig. $2 B$ ). In contrast and as expected, synaptophysin 1 was enriched in the crude synaptic vesicle fraction (LP2) (Fig. 2B), which validates our subcellular fractionation protocol. Munc13-1 was previously shown to be present in a small soluble pool and a large insoluble pool that is attached to the CAZ (Brose et al., 1995; Betz et al., 1998). When analyzing equal amounts of soluble and insoluble proteins from mouse brain homogenates by SDS-PAGE and quantitative Western blotting, we observed a soluble versus insoluble protein ratio of $0.6 \pm 0.06(n=3)$ for Munc13-1EYFP in $\mathrm{m} / \mathrm{m}$ brains and of $0.59 \pm 0.09$ $(n=3)$ for Munc13-1 in WT brains (Fig. $2 C)$. Taking into account that the total amount of pelletable protein in our mouse brain homogenates exceeded the total amount of soluble protein by a factor of $2.5 \pm 0.4(\mathrm{~m} / \mathrm{m})$ and $2.2 \pm 0.2(\mathrm{WT})$, we determined that $80 \%$ of total Munc13-1EYFP in $\mathrm{m} / \mathrm{m}$ brains and $79 \%$ of total Munc13-1 in WT brains are insoluble, which corresponds well with previously published data (Brose et al., 1995; Betz et al., 1998).

As described above, heterozygous m/+ mice showed slightly reduced expression levels of Munc13-1-EYFP compared with Munc13-1 (Figs. 1C, 2A, B). To examine whether this discrepancy is attributable to reduced Munc13-1-EYFP mRNA levels, we performed RNase protection assays to determine Munc13-1-EYFP and Munc13-1 mRNA levels in the brains of $\mathrm{m} / \mathrm{m}$ mice and WT littermates, and normalized these values using cyclophylin mRNA levels as internal controls. We found that total brain Munc13-1-EYFP mRNA levels in $\mathrm{m} / \mathrm{m}$ brains were lower $(0.12 \pm 0.04 ; n=3)$ than corresponding Munc13-1 mRNA levels in brains from WT littermates $(0.19 \pm 0.02 ; n=3)$ (Fig. $2 D)$. However, total brain protein levels of Munc13-1-EYFP (normalized to tubulin levels as loading control) in $\mathrm{m} / \mathrm{m}$ mice $(4.59 \pm 0.86 ; n=3)$ and of Munc13-1 in WT mice (4.20 $\pm 0.96 ; n=3)$ were indistinguishable (Fig. 2E).

Thus, according to our biochemical analyses, the developmental regulation of the mutated Munc13-1-EYFP gene is identical to that of the WT gene, and the subcellular distribution of Munc13-1-EYFP protein and its association with the CAZ are indistinguishable from those of WT Munc13-1. Our RNase protection assays on $\mathrm{m} / \mathrm{m}$ and WT brain mRNAs indicate either that the mutated Munc13-1-EYFP gene is transcribed less efficiently or that the Munc13-1-EYFP mRNA is less stable compared with the WT mRNA, possibly because of the presence of a loxP site and the EYFP cDNA in the $3^{\prime}$ untranslated region (Fig. $1 A$ ). This leads to lower Munc13-1-EYFP protein expression only in heterozygous $\mathrm{m} /+$ mice, whereas Munc13-1-EYFP levels in homozygous $\mathrm{m} / \mathrm{m}$ mice are almost identical to Munc13-1 levels in WT brains, indicating that the reduced levels of Munc13-1-EYFP mRNA are compensated in homozygous $\mathrm{m} / \mathrm{m}$ mice (e.g., by increases in translation), which results in identical protein expression levels of Munc13-1-EYFP and Munc13-1 in m/m and WT mice, respectively. Importantly, Munc13-1-EYFP expression never exceeds the expression of WT Munc13-1, which excludes overexpression artifacts.

Munc13-1-EYFP protein localization in Munc13-1-EYFP KIs To determine the regional, cellular, and subcellular localization of Munc13-1-EYFP in the brain, we examined by direct fluores- 
cence sagittal brain sections from $\mathrm{m} / \mathrm{m}$ mice that had been perfused with $4 \%$ paraformaldehyde. In all brain regions, the distribution of Munc13-1-EYFP was identical to that of typical general presynaptic marker proteins. Munc13-1-EYFP fluorescence was prominent in synaptic neuropil areas and absent from cell bodies and white matter (Fig. 3A). In the cerebellum, Munc13-1-EYFP was very abundant in the molecular layer, most likely representing fluorescent parallel fiber terminals, less abundant in the granule cell layer, most likely reflecting labeled axon terminals in glomeruli, and absent from the Purkinje cell layer and white matter (Fig. 3B). Corresponding sections from WT cerebellum showed only background fluorescence (Fig. 3C). In the hippocampus, Munc131-EYFP fluorescence was prominent in the stratum radiatum, stratum oriens, stratum lucidum, and hilus, which all contain dense synaptic neuropil (Fig. 3D). Lower level Munc13-1-EYFP fluorescence was detected in the stratum moleculare, and white matter was devoid of fluorescence (Fig. 3D). Again, sections from WT hippocampi only showed background fluorescence (Fig. 3E). Overall, the distribution of Munc13-1-EYFP in brains from $\mathrm{m} / \mathrm{m}$ mice was indistinguishable from the Munc13-1 distribution in WT mouse brains as detected by 3,3' -diaminobenzidine immunostaining with a Munc13-1-specific polyclonal antibody (Fig. 1A, $G$ ).

Presynaptic localization of Munc13-1EYFP was most readily detectable in the stratum lucidum, where larger fluorescent puncta that most likely correspond to mossy fiber terminals were observed (Fig. $3 F$ ). Colabeling of $\mathrm{m} / \mathrm{m}$ brain sections with an antibody to the active zone marker Bassoon revealed an almost perfect colocalization of Munc13-1-EYFP with Bassoon.

Together, our morphological data demonstrate that the EYFP tag does not interfere with the expression pattern and subcellular localization of Munc131-EYFP. It is properly targeted to presynaptic terminals and its distribution in brain is indistinguishable from that of WT Munc13-1 (for a comparison with endogenous Munc13-1 immunostaining, see Betz et al., 1998).

\section{Electrophysiological characteristics of Munc13-1-EYFP KIs}

To compare the electrophysiological characteristics of neurons expressing Munc13-1-EYFP or Munc13-1, we used hippocampal autaptic cultures from $\mathrm{m} / \mathrm{m}$ and WT control mice, a preparation that we have used in the past for the electrophysiological characterization of Munc13-1 and Munc13-2 KOs and Munc13-1 ${ }^{\mathrm{H} 567 \mathrm{~K} / \mathrm{H} 567 \mathrm{~K}}$ KIs (Augustin et al., 1999b; Betz et al., 2001; Rhee et al., 2002; Rosenmund et al., 2002; Varoqueaux et al., 2002; Junge et al., 2004). EPSC amplitudes evoked by $2 \mathrm{~ms}$ depolarizations at $0.2 \mathrm{~Hz}$ were identical in $\mathrm{m} / \mathrm{m}(-4.4 \pm 0.8$ $\mathrm{nA} ; n=38)$ and WT neurons $(-4.4 \pm 1.2 \mathrm{nA} n=32$ ) (Fig. are almost identical.
B

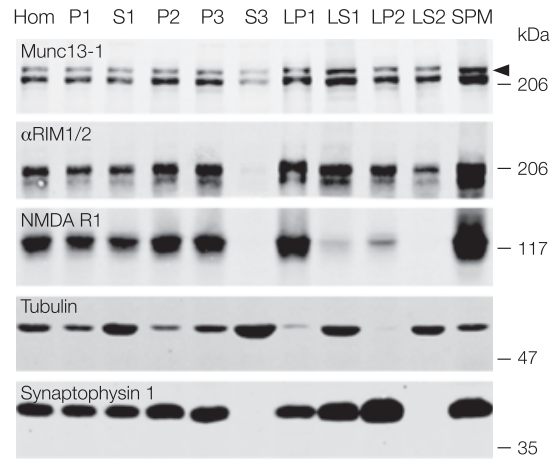

$\mathbf{E}$

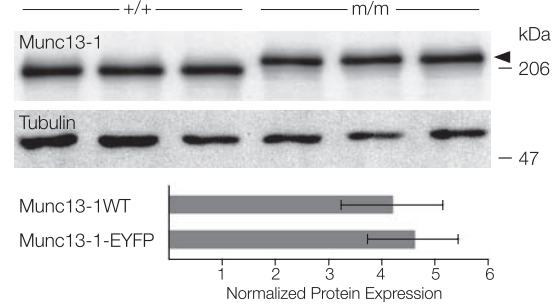

Figure 2. Munc13-1-EYFP mRNA and protein expression in Munc13-1-EYFP KI brains. $\boldsymbol{A}$, Expression of Munc13-1 and Munc13-1-EYFP protein (arrowhead) in $\mathrm{m} /+$ mice during development. Brains from mice of the indicated ages were homogenized, and proteins (10 $\mu \mathrm{g}$ per lane) were analyzed by SDS-PAGE and Western blotting with antibodies to the indicated proteins. Odyssey imaging system. The ratios between soluble and insoluble Munc13-1/Munc13-1-EYFP were calculated for each mouse and expressed as mean \pm SD $(n=3)$ (bottom panel). D. Munc13-1 and Munc13-1-EYFP mRNA expression. RNase (Munc13-1WT) and m/m (Munc13-1-EYFP) and a Munc13-1-specific mean + SD ( $=3)$. levels in homozygous WT mice (Munc13-1WT) and Munc13-1-EYFP protein levels in homozygous m/m mice (Munc13-1-EYFP)

$4 A)$. Likewise, the size of the primed, readily releasable pool (RRP) of vesicles, as assessed by integrating the total charge transfer of the transient component of the EPSC response during the pulsed application (5 s) of a hypertonic extracellular solution containing $0.5 \mathrm{~m}$ sucrose to the entire cell (Rosenmund and Stevens, 1996), was indistinguishable between $\mathrm{m} / \mathrm{m}(-438 \pm 8$ pC; $n=38)$ and WT neurons $(-439 \pm 8$ pC; $n=32$ ) (Fig. $4 B)$. These data are in contrast to Munc13-1 KO neurons, which exhibit strongly reduced evoked EPSC amplitudes and RRP sizes (Augustin et al., 1999b). We calculated the vesicular release probability $P_{\mathrm{vr}}$ for the neurons analyzed by determining the ratio of the charge transfer during an evoked EPSC and the charge transfer elicited by release of the entire RRP during the application of hypertonic sucrose solution. As predicted from the evoked EPSC and RRP measurements, $P_{\mathrm{vr}}$ values for $\mathrm{m} / \mathrm{m}$ neurons $(8.9 \pm$ $1.4 \% ; n=38)$ and WT control cells $(8.1 \pm 2.0 \% ; n=32)$ were very similar (Fig. $4 C$ ). 

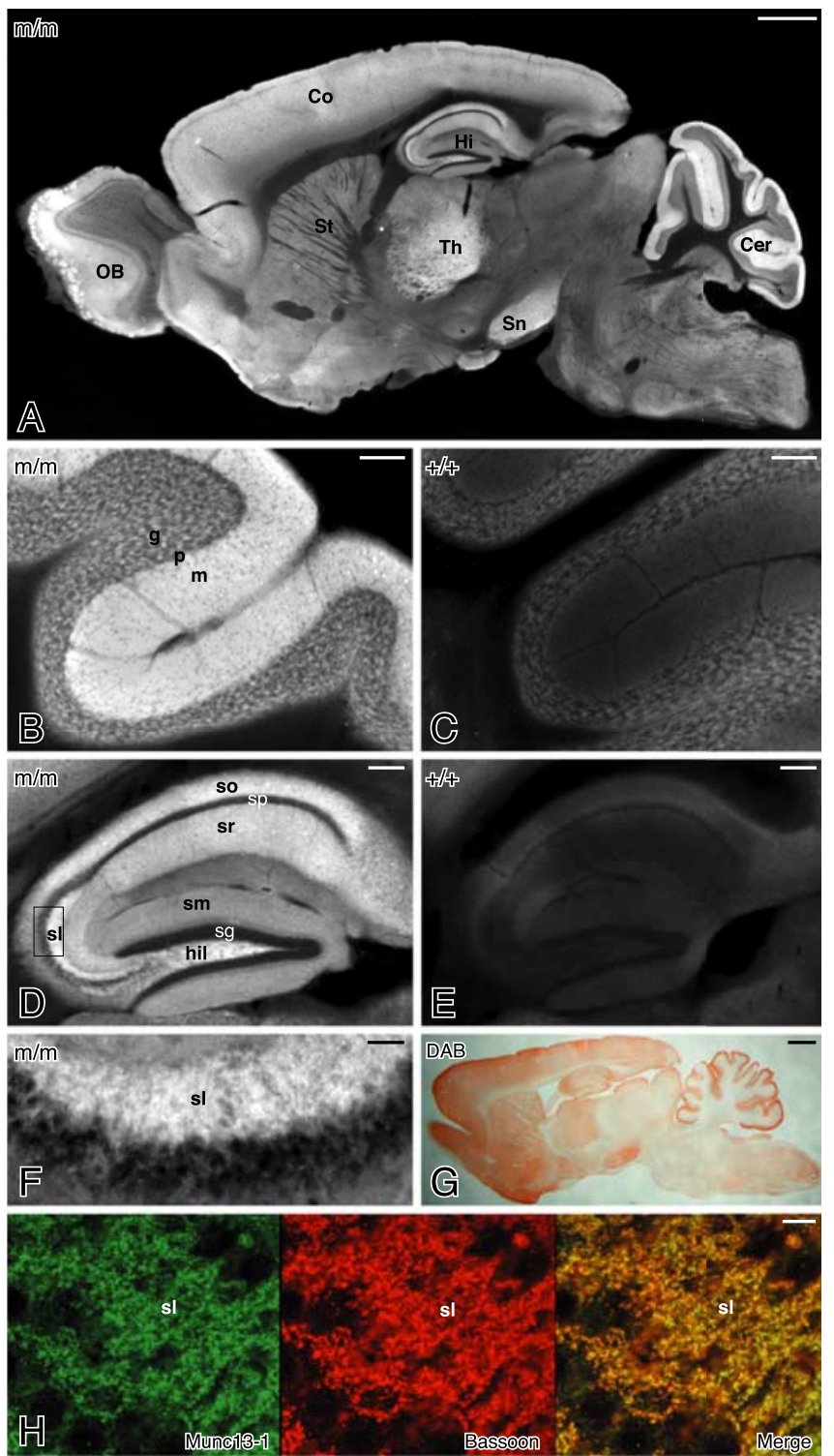

Figure 3. Regional, cellular, and subcellular localization of Munc13-1-EYFP in Munc13-1EYFP KI brains. $A$, Overview of direct Munc13-1-EYFP fluorescence in a sagittal section from a paraformaldehyde-fixed m/m mouse brain. Cer, Cerebellum; Co, cortex; Hi, hippocampus; OB, olfactory bulb; Sn, substantia nigra; St, striatum; Th, thalamus. Scale bar, $1 \mathrm{~mm}$. B, C, Higherresolution images of direct Munc13-1-EYFP fluorescence in sections through the cerebellum of $\mathrm{m} / \mathrm{m}(\boldsymbol{B})$ and WT $(+/+)$ mice $(\boldsymbol{C})$ g, Granule cell layer; $\mathrm{m}$, molecular layer; $p$, Purkinje cell layer. Scale bars, $100 \mu \mathrm{m}$. D, E, Higher-resolution images of direct Munc13-1-EYFP fluorescence in sections through the hippocampus of $\mathrm{m} / \mathrm{m}(\boldsymbol{D})$ and WT $(+/+)$ mice $(\boldsymbol{E})$. hil, Hilus; $\mathrm{sg}$, stratum granulosum; sl, stratum lucidum; sm, stratum moleculare; $s 0$, stratum oriens; $s p$, stratum pyramidale; $S$, stratum radiatum. Scale bars, $200 \mu \mathrm{m}$. F, High-resolution image of direct Munc131-EYFP fluorescence in CA3 region of the hippocampus of an $\mathrm{m} / \mathrm{m}$ mouse. $\mathrm{sl}$, Stratum lucidum; sp, stratum pyramidale. Scale bar, $25 \mu \mathrm{m}$. G, Sagittal section through the brain of a WT mouse stained for Munc13-1 using HRP-coupled secondary antibodies and 3,3'-diaminobenzidine (DAB). Note the similarity between this Munc13-1 immunostaining and direct Munc13-1-EYFP fluorescence $(\boldsymbol{A})$. Scale bar, $1 \mathrm{~mm}$. $\boldsymbol{H}$, Images of sections through the CA3 region of the hippocampus of an $\mathrm{m} / \mathrm{m}$ mouse after fluorescence immunostaining for the active zone marker Bassoon (red). Note the coincidence (yellow) of direct Munc13-1-EYFP fluorescence (green) and Bassoon-positive structures (red) in mossy fiber terminals of the stratum lucidum (sl). Scale bar, $10 \mu \mathrm{m}$

We found previously that Munc13-1 mediates the potentiating effects of phorbol esters on evoked EPSC amplitudes in autaptic hippocampal neurons by acting as a direct phorbol ester receptor (Rhee et al., 2002). We therefore compared the stimula- tory effects of 4 - $\beta$-phorbol-12,13-dibutyrate (PDBu) on evoked EPSC amplitudes in $\mathrm{m} / \mathrm{m}$ and WT control neurons, but found no differences. PDBu, applied at $1 \mu \mathrm{M}$ for $1 \mathrm{~min}$, potentiated evoked EPSC amplitudes to a similar degree in $\mathrm{m} / \mathrm{m}$ (1.67 \pm 0.10 -fold; $n=16)$ and WT control cells $(1.70 \pm 0.20$-fold; $n=18)$ (Fig. $4 D)$. These data are in contrast to Munc13-1 ${ }^{\mathrm{H} 567 \mathrm{~K} / \mathrm{H} 567 \mathrm{~K}} \mathrm{KI}$ neurons, which express a phorbol ester binding deficient Munc13$1^{\mathrm{H} 567 \mathrm{~K}}$ variant and whose evoked EPSCs are insensitive to phorbol esters (Rhee et al., 2002).

As a typical short-term plasticity characteristic, WT hippocampal neurons exhibit synaptic depression during highfrequency stimulation trains of $10-50 \mathrm{~Hz}$. We found previously that this depression is dependent on the presence of Munc13-1 and converted to frequency facilitation in Munc13-1 KO neurons (Rosenmund et al., 2002). We therefore studied short-term synaptic plasticity in $\mathrm{m} / \mathrm{m}$ and WT control neurons during 10 and 50 $\mathrm{Hz}$ stimulation trains. On stimulation at $10 \mathrm{~Hz}$, evoked EPSCs in both $\mathrm{m} / \mathrm{m}(n=16)$ and WT neurons $(n=18)$ depressed rapidly and exactly in parallel, reaching a plateau at $\sim 40 \%$ of the initial EPSC amplitude after 10-20 stimuli (Fig. 4E). Likewise, trains of five stimuli given at $50 \mathrm{~Hz}$ resulted in exactly the same time course of synaptic depression in $\mathrm{m} / \mathrm{m}(n=16)$ and WT control cells $(n=18)$ (Fig. 4F).

Together, our electrophysiological data demonstrate that the transmitter release characteristics of $\mathrm{m} / \mathrm{m}$ neurons are exactly identical to those of WT cells. This is in striking contrast to all other Munc13 mouse mutants studied so far (Augustin et al., 1999b; Rhee et al., 2002; Rosenmund et al., 2002; Varoqueaux et al., 2002) and indicates that the priming activity of Munc13-1EYFP is indistinguishable from that of WT Munc13-1.

\section{Characterization of Munc13-1-EYFP protein localization in primary culture}

Our characterization of Munc13-1-EYFP expression in wholebrain sections already indicated that the fusion protein is targeted properly to presynaptic terminals (Fig. $3 H$ ). However, the resolution of this characterization is limited by the high density of synapses in sections. Therefore, we further characterized the cellular distribution of Munc13-1-EYFP in primary cultures of dissociated neurons prepared from the hippocampus and cerebral cortex of newborn Munc13-1-EYFP KI mice. As expected, Munc13-1-EYFP exhibited a punctate distribution that was detected from $\sim 6$ to 7 DIV onward (Fig. $5 A-F$ ). Munc13-1-EYFP puncta were readily resolved by laser-scanning confocal microscopy, and exhibited fluorescence levels that were only slightly lower than those of other GFP-tagged synaptic proteins (such as Bassoon, PSD-95, NMDAR1) expressed by conventional means in cultured neurons (Bresler et al., 2001, 2004). Thus, there was no need for extreme excitation intensities or long integration times to obtain satisfactory images. On the other hand, the EYFP moiety was somewhat sensitive to photobleaching, and this posed some limitations on time-lapse sampling rates and durations.

To determine whether Munc13-1-EYFP puncta represented functional sites of synaptic vesicle recycling, we used the styryl dye FM4-64 and field stimulation to label functional synaptic vesicle recycling sites (Vardinon-Friedman et al., 2000) and compared the spatial distribution of Munc13-1-EYFP and FM4-64 puncta. The vast majority of Munc13-1-EYFP puncta colocalized with sites that exhibited a capacity to uptake FM4-64 in response to stimulation $(60 \mathrm{~s}$ at $10 \mathrm{~Hz})$, and then release it in response to a second stimulus train $(120 \mathrm{~s}$ at $10 \mathrm{~Hz})$, indicating that Munc131-EYFP-positive puncta represent functional sites of evoked synaptic vesicle endocytosis and exocytosis (Fig. 5D-I). 
Munc13-1-EYFP puncta usually appeared to be smaller than FM4-64 puncta or presynaptic terminals immunolabeled for synaptic vesicle-associated proteins such as synapsin I and VAMP2 (vesicleassociated membrane protein 2) (data not shown). As described above, Munc13-1 is one of a small group of active zone cytomatrix proteins, which collectively form the active zone subregion of presynaptic boutons. To confirm the active zone localization of Munc13-1-EYFP, we fixed Munc13-1-EYFP KI primary culture preparations and immunolabeled them for the CAZ protein Piccolo. The patterns of Munc13-1-EYFP fluorescence and antiPiccolo immunofluorescence were almost identical (Fig. 5J-L). Furthermore, when Munc13-1-EYFP fluorescence intensity was compared with anti-Piccolo immunofluorescence intensity at the level of individual puncta, a high correlation was found between these two datasets (Fig. 5M).

Our previous studies showed that GABAergic synapses, unlike most glutamatergic synapses, retain their functionality in neurons of Munc13-1 KO mice (Augustin et al., 1999b), a phenomenon that was later shown to be attributable to a complete redundancy of Munc13-1 and Munc13-2 in GABAergic synaptic terminals (Varoqueaux et al., 2002). To determine whether Munc13-1-EYFP is found at active zones of both GABAergic and glutamatergic synapses, as would be predicted, we examined the colocalization of Munc13-1-EYFP with VGluT1 (a marker for glutamatergic presynaptic boutons) and VIAAT (a marker for GABAergic presynaptic boutons). We found that Munc13-1-EYFP colocalized with both VGluT- and VIAAT-positive axon terminals (Fig. $5 N-Q$ ), although in some cases the correlation at the level of individual puncta between Munc13-1-EYFP fluorescence intensity and VIAAT immunofluorescence intensity was less consistent than that observed between Munc13-1-EYFP fluorescence and VGluT1 immunofluorescence intensities (data not shown).

The localization of Munc13-1-EYFP puncta relative to that of postsynaptic components of glutamatergic synapses (PSD-95, GluR1, ProSAP2) was also examined by immunocytochemical and direct fluorescence analysis of cultured neurons. This analysis revealed a close apposition between Munc13-1-EYFP with these postsynaptic markers in most but not all synapses (data not shown), as would be expected because of the presence of nonglutamatergic Munc13-1-EYFPpositive presynapses in these preparations.
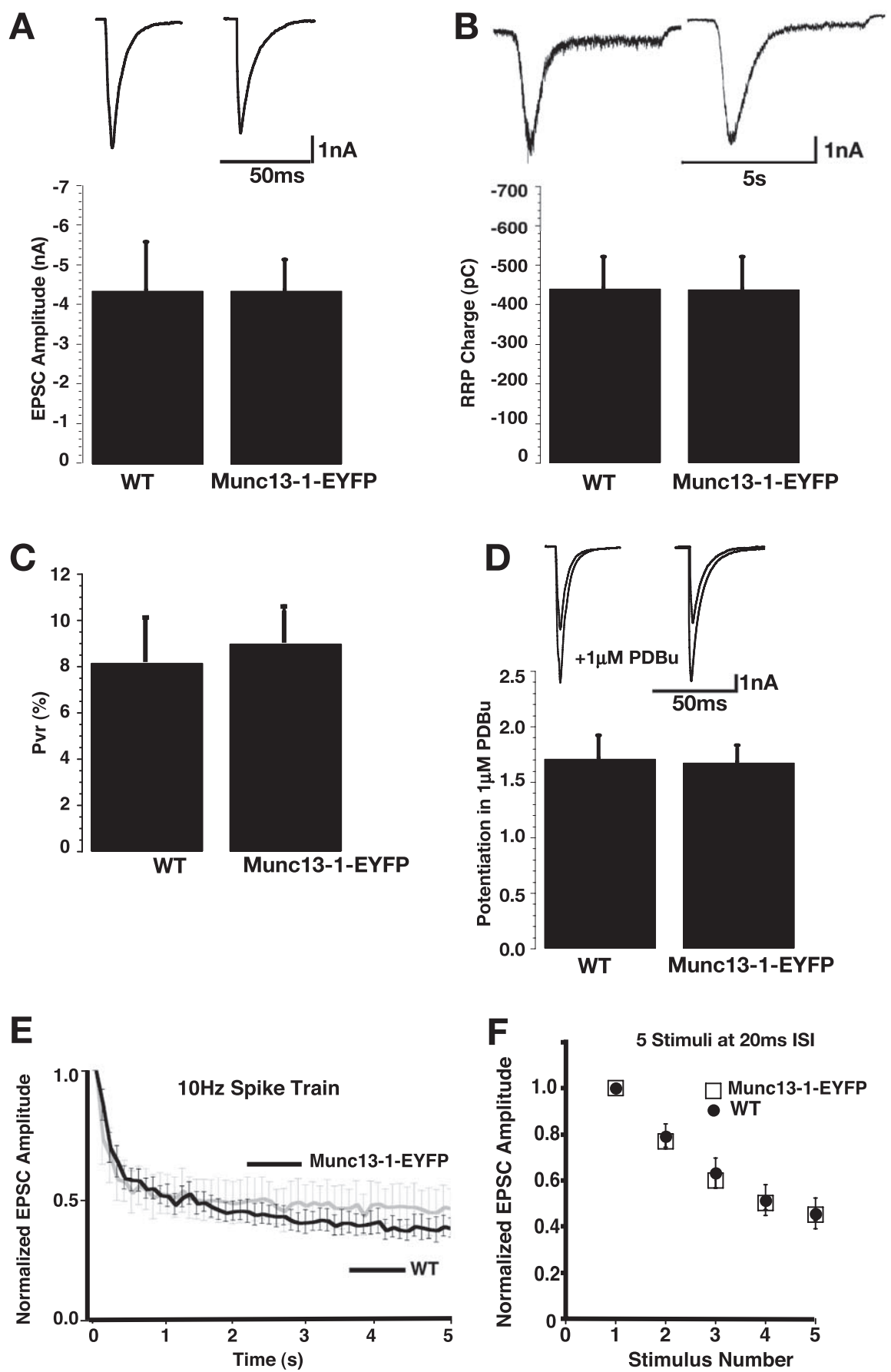

Figure 4. Transmitter release in Munc13-1-EYFP KI neurons. A, Sample traces (top panel) and average evoked EPSC amplitudes (bottom panel) in WT and $\mathrm{m} / \mathrm{m}$ (Munc13-1-EYFP) neurons. For each cell, EPSC amplitudes of $13-20$ pulses at $0.2 \mathrm{~Hz}$ were averaged. Data are expressed as mean \pm SEM. B, Sample traces of RRP measurements (top panel) and average RRP sizes in WT and $\mathrm{m} / \mathrm{m}$ neurons (Munc13-1-EYFP) (bottom panel). Cells were stimulated with hypertonic sucrose solutions as described in the text. Data are expressed as mean \pm SEM. $C$, Average $P_{\mathrm{vr}}$ in WT and $\mathrm{m} / \mathrm{m}$ neurons (Munc13-1-EYFP). $P_{\mathrm{vr}}$ was calculated as described in Results. Data are expressed as mean \pm SEM. D, Sample traces (top panels) of evoked EPSCs in WT and $\mathrm{m} / \mathrm{m}$ (Munc13-1-EYFP) neurons before (black traces) and after (gray traces) treatment with $1 \mu \mathrm{m} \mathrm{PDBu}$, and average PDBu-induced potentiation of evoked EPSCs in WT and $\mathrm{m} / \mathrm{m}$ (Munc13-1-EYFP) neurons (bottom panel). Data are expressed as mean \pm SEM. $\boldsymbol{E}$, Short-term plasticity of EPSCs in WT (black; WT; $n=18$ ) and $\mathrm{m} / \mathrm{m}$ (gray; Munc13-1-EYFP; $n=16$ ) neurons during a $10 \mathrm{~Hz}$ stimulation train. Neurons were initially stimulated at $0.2 \mathrm{~Hz}$ stimulation frequency (data not shown), and then a $10 \mathrm{~Hz}$ train was applied for $5 \mathrm{~s}$. EPSC amplitudes were normalized to the average EPSC amplitude of the first nine data points at $0.2 \mathrm{~Hz}$ stimulation frequency. Data are expressed as mean \pm SEM. $F$, Short-term plasticity of EPSCs in WT (filled circles; WT; $n=18$ ) and $\mathrm{m} / \mathrm{m}$ (open squares; Munc13-1-EYFP; $n=16$ ) neurons during $50 \mathrm{~Hz}$ stimulation. Neurons were initially stimulated at $0.2 \mathrm{~Hz}$ stimulation frequency (data not shown), and then a $50 \mathrm{~Hz}$ train of five stimuli was applied. EPSC amplitudes were normalized to the average EPSC amplitude of the first nine data points at $0.2 \mathrm{~Hz}$ stimulation frequency. Data are expressed as mean $\pm \mathrm{SEM}$. 

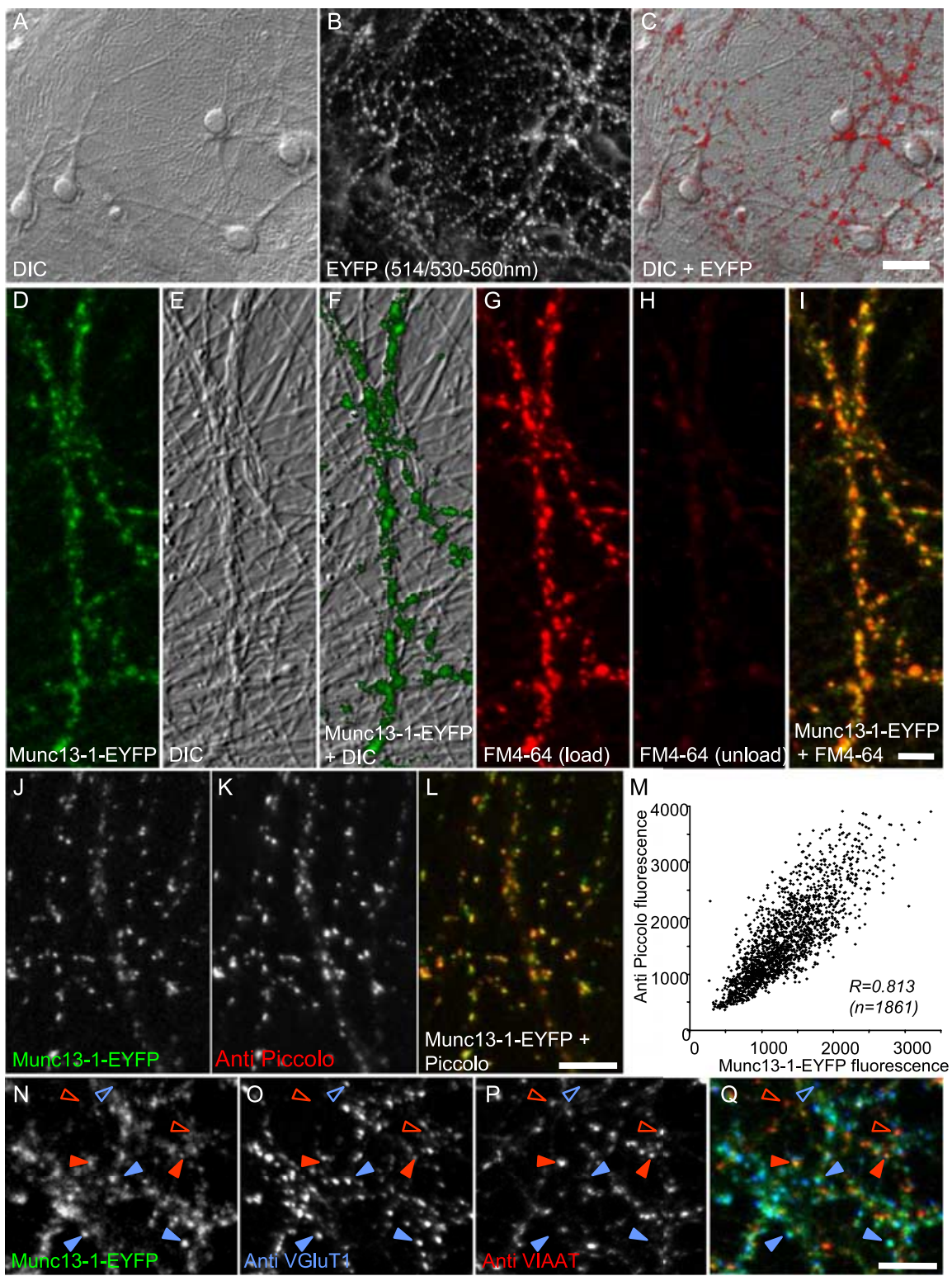

Figure 5. Presynaptic localization of Munc13-1-EYFP in primary cultures of Munc13-1-EYFP KI neurons. $A$, DIC image of hippocampal neurons obtained from Munc13-1-EYFP KI and grown in culture for $17 \mathrm{~d}$. $\boldsymbol{B}$, Fluorescence image of Munc13-1-EYFP puncta in the same field of view. $\boldsymbol{C}$, Fluorescence image overlaid onto DIC image. $\boldsymbol{D}-\boldsymbol{F}$, Higher magnification of Munc13-1-EYFP puncta overlaid onto DIC image of the same region. $\boldsymbol{G}, \boldsymbol{H}$, Same region as in $\boldsymbol{D}-\boldsymbol{F}$ after functional presynaptic sites were labeled with FM4-64 by stimulating the neurons to fire action potentials $(60 \mathrm{~s}$ at $10 \mathrm{~Hz})$ in the presence of the dye $(\boldsymbol{G})$, and after unloading the dye $(\boldsymbol{H})$ with a second train of action potentials $(120 \mathrm{~s}$ at $10 \mathrm{~Hz}) . \boldsymbol{I}$, Combined image of Munc13-1-EYFP (D) and FM4-64 (G). Note the high spatial correspondence between Munc13-1-EYFP and FM4-64 puncta. $J-L$, Neurons fixed and immunolabeled for Piccolo. Note the nearly perfect match between Munc13-1-EYFP- and Piccolo-immunopositive puncta. $M$, Correlation between the intensity of Munc13-1-EYFP fluorescence and the anti-Piccolo immunofluorescence for the same puncta (1861 puncta). $\mathbf{N}-\mathbf{Q}$ Neurons double labeled for VGluT1/2 (blue) and VIAAT (red) and imaged for direct Munc13-1-EYFP fluorescence (green). Munc13-1-EYFP colocalizes with VGluT1/2 (filled blue arrowheads) and VIAAT (filled red arrowheads). Only very few VGluT1/2- or VIAAT-positive synapses appear to contain very little or no Munc13-1-EYFP (examples are indicated by open blue and red arrowheads). Scale bars: $\mathbf{A}-\mathbf{C}, 20 \mu \mathrm{m} ; \mathbf{D}-\mathbf{I}, 5 \mu \mathrm{m} ; \boldsymbol{J}-\mathbf{Q}, 10 \mu \mathrm{m}$.

In summary, the above experiments demonstrate that expression levels of Munc13-1-EYFP in Munc13-1-EYFP KI mice are suitable for informative fluorescence imaging. The data also confirm that Munc13-1-EYFP is targeted correctly to functional presynaptic sites. The near-perfect spatial coincidence and quantitative correlation of Munc13-1-EYFP and Piccoloimmunopositive puncta strongly support the notion that
Munc13-1-EYFP is targeted correctly to presynaptic active zones.

Regulation of Munc13-1-EYFP levels by proteasome-dependent degradation

Studies in Drosophila indicated that the Drosophila Munc13 homolog DUNC-13 is constantly synthesized and degraded at high rates. Indeed, the effective concentration of DUNC-13 at Drosophila synapses appears to be controlled locally by proteasome-dependent degradation, whose rate, in turn, is dynamically regulated by multiple signaling mechanisms (Aravamudan and Broadie, 2003; Speese et al., 2003). Given that the genetic regulation of Munc13-1-EYFP expression was unperturbed in Munc13-1-EYFP KI mice, our mouse model allowed us to examine whether the complex proteasomal regulation of DUNC-13 levels observed in Drosophila also occurs in the case of murine Munc13-1.

To that end, we used automated multisite time lapse confocal microscopy to follow the fluorescence levels of Munc13-1EYFP puncta in cultured neurons from Munc13-1-EYFP KI mice, before and after the addition of a pharmacological agent that inhibits proteasome-mediated protein degradation (MG132; $20 \mu \mathrm{M})$. Coverslips with neurons were mounted on the stage of a custom-built confocal microscope system in an enclosure that provided a sterile atmospheric environment of 5\% $\mathrm{CO}_{2}, 95 \%$ air. The chamber and objective of the inverted microscope were heated to $37-38^{\circ} \mathrm{C}$, resulting in intrachamber temperatures of $33-35^{\circ} \mathrm{C}$. In Drosophila, pharmacological inhibition of proteasomemediated protein degradation resulted in an approximately twofold increase in DUNC-13 concentration within $45 \mathrm{~min}$ (Speese et al., 2003). We therefore followed fluorescence levels of Munc13-1EYFP puncta for $3 \mathrm{~h}$ after MG132 addition, imaging once every $30 \mathrm{~min}$ at multiple sites of each coverslip. However, we did not observe any increase in Munc13-1-EYFP puncta fluorescence (two experiments; 11 fields of view) (data not shown). We thus increased the duration of the experiment to $12-14 \mathrm{~h}$ and reduced sampling rates to one image every $2 \mathrm{~h}$ to minimize photobleaching. However, we were still unable to detect increases in Munc13-1-EYFP fluorescence after MG132 addition (Fig. 6) and only observed slight decreases in fluorescence over 12-14 h (three experiments; 15 fields of view; 6112 puncta). These decreases may have been caused by photobleaching, but, in fact, similar reductions ( $\sim 4 \%$ over $12-14 \mathrm{~h}$ ) were observed during the same experiments in fields of view that were only sampled twice, at the beginning of the experiment and at its end ( 15 fields 

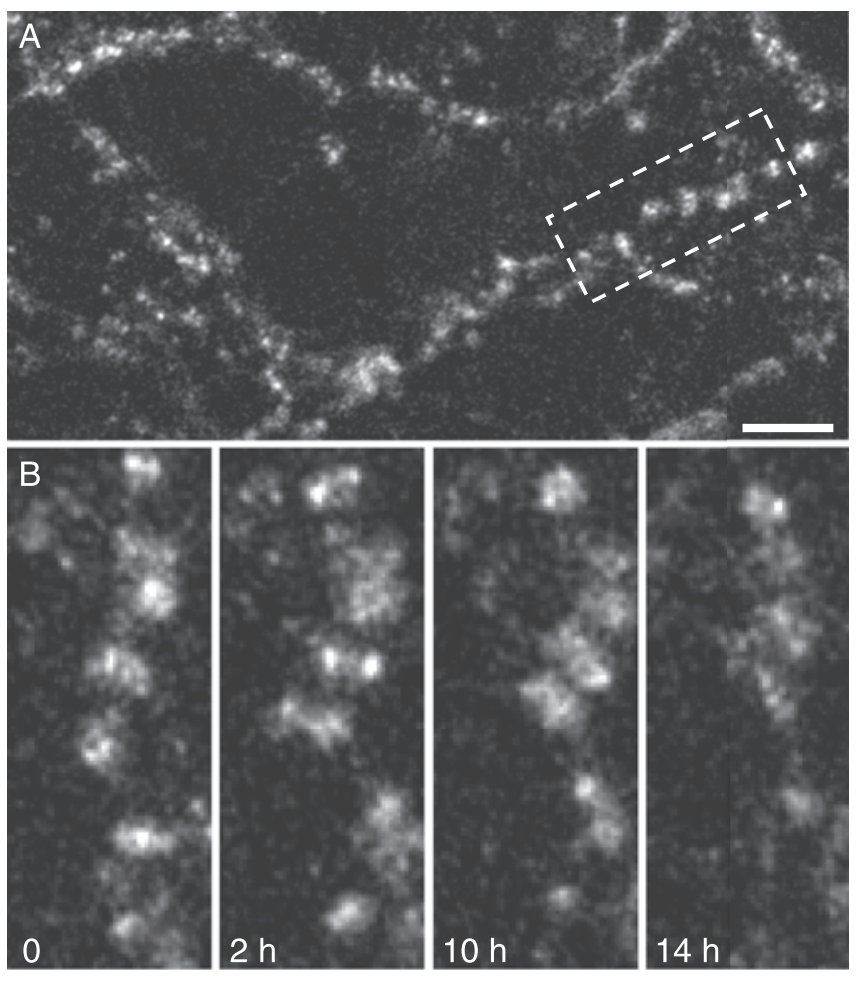

C

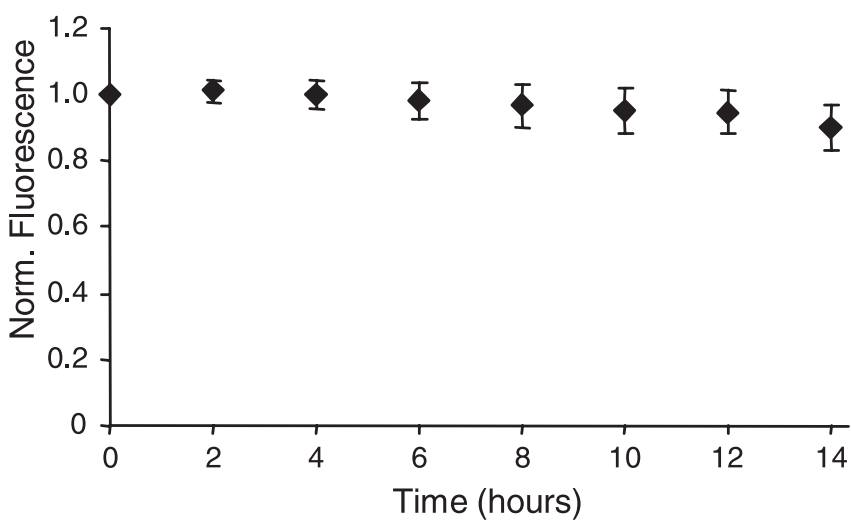

Figure 6. Effects of proteasomal protein degradation on steady-state Munc13-1-EYFP levels. $\boldsymbol{A}$, Fluorescence image of Munc13-1-EYFP puncta in cultured neurons isolated from the cerebral cortex of Munc13-1-EYFP mice. Scale bar, $10 \mu \mathrm{m}$. B. Higher magnification of the region enclosed by a rectangle in $A$. After obtaining the first image, MG132, a potent inhibitor of proteasomal protein degradation, was added to the extracellular medium, and images were collected at $2 \mathrm{~h}$ intervals. Only four of nine images collected in this experiment are shown here. C, Mean Munc13-1-EYFP puncta fluorescence over time. Because of gradual changes in the positions of individual puncta over the long durations of these experiments, it was difficult to track individual puncta reliably over the entire experiment. We thus determined programmatically the average fluorescence intensity of all Munc13-1-EYFP puncta in each field of view and normalized these values by dividing them by the average puncta fluorescence for that field of view at time $t=0$. Note that no overall increases in Munc13-1-EYFP fluorescence were observed [ 3 separate experiments; 15 fields of view; 6112 puncta (mean total count)]. Error bars indicate SD.

of view; 6221 puncta) (supplemental Fig. 1, available at www.jneurosci.org as supplemental material). We therefore cannot rule out the possibility that this modest reduction is real, but we can safely state that the addition of MG132 did not increase Munc131-EYFP fluorescence as observed for DUNC-13 in Drosophila neuromuscular junctions. Similar experiments were performed in the presence of the protein synthesis inhibitor cycloheximide
$(100 \mu \mathrm{M})$. Not surprisingly, perhaps, the addition of cycloheximide resulted only in a modest and gradual decrease in puncta fluorescence (12-15\% over 7-14 h; two experiments; 16 fields of view; 5823 puncta) (data not shown).

Together, these data indicate that Munc13-1 levels at active zones are not controlled by rapid synthesis and counteracting proteasome-mediated degradation. We cannot formally exclude the possibility that the EYFP tag at the C terminus of Munc13-1 interferes with Munc13-1-EYFP synthesis or its proteasomemediated degradation. However, this scenario is rather unlikely, because under normal conditions Munc13-1-EYFP levels in homozygous KI mice are not different from Munc13-1 levels in WT mice (Fig. 1C). This would only be compatible with a confounding effect of the EYFP tag on Munc13-1 synthesis and stability if the tag reduced the synthesis and degradation rates of Munc13$1-E Y F P$ by exactly the same degree.

\section{Exchange rates of Munc13-1-EYFP at individual synapses}

Recent studies indicated that several components of the presynaptic cytomatrix exhibit considerable dynamics, which are often accelerated by synaptic activation (Chi et al., 2001; Inoue and Okabe, 2003; Sankaranarayanan et al., 2003; Mueller et al., 2004; Star et al., 2005; Tsuriel et al., 2006). However, the majority of these studies were based on the expression of GFP-tagged variants of synaptic proteins from corresponding expression vectors, followed by live imaging of protein transport and turnover. As explained above, these standard expression methods often lead to nonphysiological expression levels (overexpression), which may confound the validity of conclusions drawn from such experiments. In contrast, Munc-13-1-EYFP expression levels in Munc13-1-EYFP KI mice are identical to WT Munc13-1 expression levels and subject to the same developmental and cellular regulatory processes, thus providing a unique opportunity to examine the molecular dynamics of a critical presynaptic protein in a minimally perturbed system.

We applied FRAP microscopy to explore the rates at which Munc13-1-EYFP is lost from and reincorporated into individual presynaptic active zones and the dependence of these rates on both acute and chronic manipulations of synaptic activity. To that end, cultured cortical neurons from Munc13-1-EYFP KI mice were mounted on the stage of a custom-built confocal microscope system, and superfused slowly with a preheated physiological saline solution while warming the objective and chamber to $37-38^{\circ} \mathrm{C}$. To minimize spontaneous activity, the glutamate receptor blockers CNQX $(10 \mu \mathrm{M})$ and AP-5 $(50 \mu \mathrm{M})$ were added to the perfusion solution. After collecting baseline images, two to four Munc13-1-EYFP puncta were selectively bleached by highintensity $514 \mathrm{~nm}$ laser light using an acousto-optical tunable filter (AOTF) to selectively illuminate regions of $2 \times 2 \mu \mathrm{m}(12 \times 12$ pixels) centered on these puncta. Munc13-1-EYFP puncta were photobleached under the control of a computer program until their fluorescence was reduced to $\sim 40 \%$ of their initial level, after which fluorescence recovery (indicating the loss of bleached molecules from the presynaptic site and the incorporation of unbleached molecules from outside the photobleached region) was monitored by automated time-lapse confocal microscopy.

In initial experiments, Munc13-1-EYFP fluorescence recovery was recorded once every 1-3 min. However, these high sampling rates were associated with considerable photobleaching ( $\sim 40 \%$ reduction in the fluorescence of nonbleached neighboring puncta over $1 \mathrm{~h}$ ) (data not shown). We thus adopted an adaptive sampling rate suited to optimally sample recovery curves similar to those generated in initial experiments (Fig. 7A- 


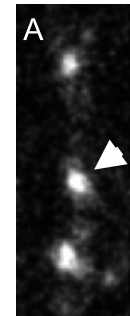

before

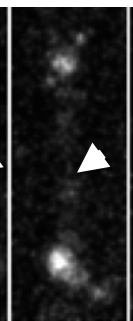

bleach

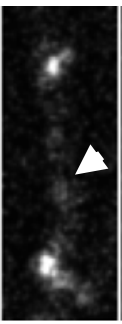

5

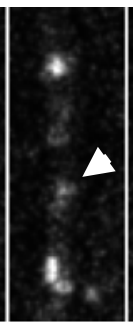

15

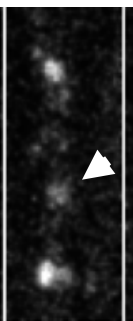

35

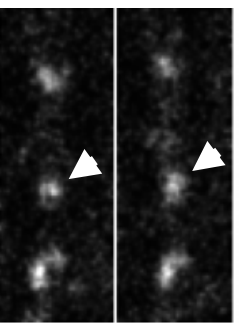

65
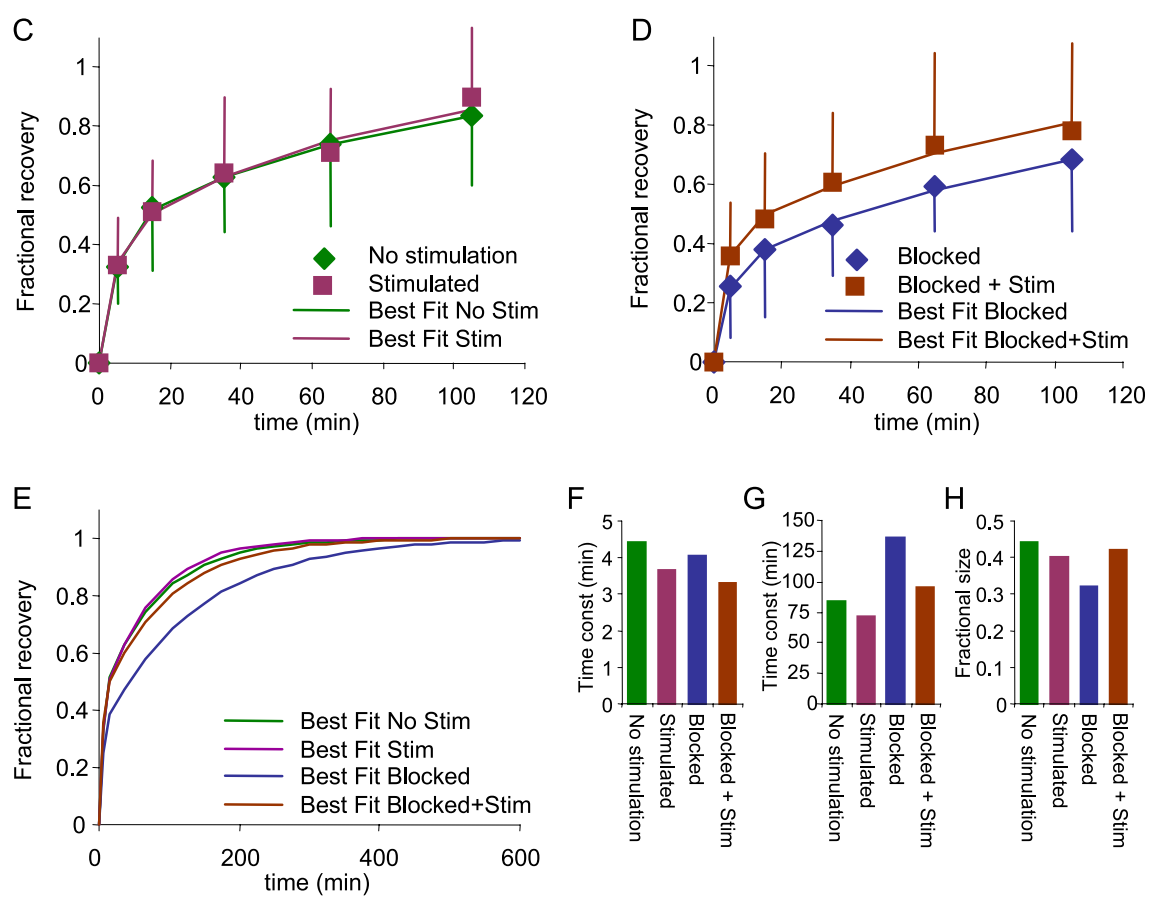

Figure 7. Exchange kinetics of Munc13-1-EYFP at individual presynaptic sites. A, Small field of view enclosing three Munc131 -EYFP puncta. At time $t=0$, one of these puncta (arrow) was selectively photobleached by high-intensity laser light. Fluorescence recovery at these sites was then followed by time-lapse imaging at increasingly longer time intervals (as explained in Results). $\boldsymbol{B}$, At the end of the experiment, presynaptic boutons were labeled (load) with FM4-64 (60 s at $10 \mathrm{~Hz}$ ) followed by unloading (120 s at $10 \mathrm{hz}$ ) to verify the functionality of the photobleached presynaptic site (bottom panels). Note that the photobleached Munc13-1-EYFP punctum exhibited a capacity for evoked endocytosis and exocytosis of FM4-64. Only puncta that exhibited such a capacity were included in our analysis. Times are given in minutes from photobleaching. Scale bar, $3 \mu \mathrm{m}$. $\boldsymbol{C}$, Munc13-1-EYFP fluorescence recovery curves. All experiments were performed in the presence of CNQX (10 $\mu \mathrm{M})$ and AP-5 (50 $\mu \mathrm{M})$ to minimize spontaneous activity. In some of the experiments, neurons were stimulated at $20 \mathrm{~Hz}$ for $20 \mathrm{~s}$ every 3 min, with stimulation starting immediately after collecting the first post-photobleach image (Stimulated; $n=9$ ), whereas in the remainder, no stimulation was performed $(n=14)$. Data shown are mean \pm SD for all photobleached puncta after correcting for ongoing photobleaching and normalization as described in Materials and Methods. Only one-sided error bars are shown for clarity. D, Munc13-1-EYFP fluorescence recovery curves in neurons grown for 4-8 din CNQX and AP-5. After performing an initial set of FRAP experiments (Blocked; $n=14$ ) a second set of FRAP experiments was performed in the same preparations (Blocked + Stim; $n=7$ ) while stimulating the neurons during the recovery phase as described in $\boldsymbol{C}$. $\boldsymbol{E}$, Comparison of best-fit recovery functions for all conditions. Note that recovery kinetics in all conditions were very similar except those measured after prolonged activity blockade (Blocked). $\boldsymbol{F}-\boldsymbol{H}$, Values of time constants of fast $(\boldsymbol{F})$ and slow $(\boldsymbol{G})$ pools and relative pool sizes $(\boldsymbol{H})$ that provide the best fits for the FRAP experimental data in $\boldsymbol{C}$ and $\boldsymbol{D}$ and that were used to generate the curves shown in $\boldsymbol{C}-\boldsymbol{E}$.

C). Furthermore, all fluorescence recovery data were corrected for ongoing photobleaching by dividing the normalized fluorescence of the bleached puncta by the normalized fluorescence of 10 nonbleached boutons at each time point (see Materials and Methods).

To verify that the bleaching procedure did not impair the functionality of the photobleached presynaptic sites, field stimulation $(10 \mathrm{~Hz} ; 60 \mathrm{~s})$ was used to label all boutons in the fields of view with FM4-64. In agreement with previous studies (Krasze-

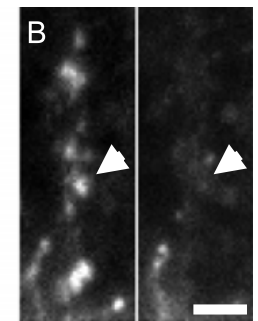

FM 4-64 FM 4-64

load unload
$\mathrm{H}$

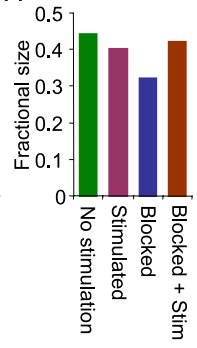

wski et al., 1996; Li and Murthy, 2001; Darcy et al., 2006; Tsuriel et al., 2006), presynaptic sites typically remained functional after the photobleaching procedure. In any case, only photobleached puncta that exhibited a capacity to recycle FM4-64 were included in our analysis.

To test whether Munc13-1-EYFP exchange rates are affected by increasing presynaptic activity and concomitant presynaptic molecular dynamics associated with neurotransmitter release, we repeated FRAP experiments as described above, but the preparations were stimulated for $20 \mathrm{~s}$ at $20 \mathrm{~Hz}$ every $3 \mathrm{~min}$ after obtaining the first post-photobleaching image. As before, glutamate receptor blockers were added to the perfusion solution to eliminate spontaneous activity. Acute stimulation had no detectable effect on Munc131-EYFP exchange kinetics (Fig. 7).

Because the in vitro networks of cortical neurons used in the present study exhibit significant spontaneous activity (data not shown), it remained possible that the rather short duration of activity blockade during the experiments described above was not sufficiently long to unmask potential differences in Munc13-1-EYFP exchange kinetics between stimulated and nonstimulated active zones. We thus grew cultures in the presence of the aforementioned glutamate receptor blockers for 4-8 d, and performed identical FRAP experiments in these preparations and untreated control cultures. Interestingly, the long-term blockade reduced Munc13-1EYFP exchange kinetics by a small but discernable amount (Fig. 7D). Remarkably, when a second set of Munc13-1-EYFP puncta were photobleached in the very same preparations and stimulated as described above, fluorescence recovery kinetics returned immediately to preblockade values.

The fluorescence recovery curves in all FRAP experiments could not be fit satisfactorily to single exponentials but could be approximated well by a recovery function composed of two exponentials. This may indicate the existence of two pools of Munc13-1-EYFP that exhibit different exchange kinetics (Tsuriel et al., 2006). We thus used a computer program to find the best fit of the experimental data to a recovery function composed of two exponentials and thus obtain two time constants and the relative sizes of the two pools that best describe the data (three degrees of freedom). These fits indicated that the exchange time constants for the fast and slow exchanging pools are $\sim 3$ and $\sim 80 \mathrm{~min}$, respectively, and that the fast versus slow pool size ratio is $\sim 4: 6$ (Fig. 7). Furthermore, extrapolation of these recovery curves (Fig. 7E) indicated that almost all Munc13-1-EYFP at individual active zones is exchanged over $\sim 4 \mathrm{~h}$ in active neurons, and over $\sim 8 \mathrm{~h}$ in 
neurons grown chronically in glutamate receptor blockers. Finally, our analysis indicates that the slower exchange kinetics observed after long-term activity blockade are attributable to a reduction in the fractional size of the fast exchanging pool and a reduction in the exchange rates exhibited by the slow pool.

Together, above experiments indicate that Munc13-1 at active zones is continuously exchanged with Munc13-1 from extrasynaptic sources. These data support the emerging view that presynaptic multimolecular protein matrices such as the CAZ are highly dynamic entities despite the fact that their components interact with each other with rather high affinity.

\section{Discussion}

\section{Methodological considerations}

The analysis of synaptic function has been revolutionized by the introduction of GFP and its many spectral and functional variants. However, the methods used to introduce GFP-fusion proteins into cells and induce their expression are nearly always associated with nonphysiological quantitative and temporal expression characteristics, leaving a significant level of insecurity as to the physiological relevance of corresponding data. The current study shows that a much closer to optimal solution, the KI approach, is feasible and useful for studying synaptic function.

Munc13-1-EYFP KI mice are viable, healthy, and show no defects in synaptic transmission. The fluorescence signals obtained from synapses in brain sections and cultured neurons are sufficiently high for detection by direct fluorescence (Fig. 3) and for imaging presynaptic Munc13-1-EYFP in living neurons (Figs. 5-7), although Munc13-1-EYFP expression levels do not exceed levels of WT Munc13-1. Although the fused EYFP cDNA appears to slightly affect Munc13-1 mRNA synthesis (Fig. 2D), Munc131-EYFP protein expression rates and steady-state expression levels in $\mathrm{m} / \mathrm{m}$ mice are indistinguishable from WT Munc13-1 levels (Fig. 2E), indicating that this mouse model represents a minimally perturbed and useful experimental model.

A critical issue of our KI strategy concerns the choice of the EYFP tag. An alternative approach would have been to use a tetracysteine tag (CCXXCC), which specifically binds to arsenoxide derivatives of fluorophores such as FlAsH and $\mathrm{ReAsH}$ (Griffin et al., 2000). Because of its small size, the tetracysteine tag is less likely to interfere with protein function. On the other hand, cells must be labeled with FlAsH/ReAsH for every experiment, a significant perturbation because of the toxicity of these fluorophores. Furthermore, in vivo studies with these reagents are difficult to perform at present. In any case, our data show that the C-terminal EYFP tag in Munc13-1-EYFP does not interfere with steady-state protein levels (Fig. 2E), subcellular localization (Figs. 2 B, C, 3, 5) [compare with Betz et al. (1998) and Rhee et al. (2002)], or function (Fig. 4).

Because Munc13-1 is a ubiquitous marker of active zones, our mice should facilitate more general in vitro or in vivo studies on synapse and network formation and experiments that require the ad hoc identification of presynaptic terminals. In this respect, two possible disadvantages of our KI mouse model require attention. The first concerns the fact that Munc13-1-EYFP is expressed in all synapses, which is different from the mosaic expression pattern typically preferred for in vivo imaging, such as that seen in mice expressing GFP variants from the Thy1.2 promoter (Feng et al., 2000). This problem is extremely difficult to circumvent with available mouse KI technologies. Still, although mosaic transgenics offer advantages for imaging individual synaptic structures of single neurons, there are scenarios in which the ability to visualize all presynaptic structures would be highly advantageous. For ex- ample, pansynaptic labeling would be desirable for analyzing synapse population dynamics during development, aging, after specific insults, or in mouse models of neurodegenerative diseases. Also, scenarios in which imaging of both presynaptic and postsynaptic structures is of interest would benefit from pansynaptic labeling. For example, studying sparsely labeled dendritic spines in an environment in which all presynaptic sites are tagged and spectrally separable would allow to determine whether and when dendritic spines become associated with presynaptic counterparts, an issue usually addressed by retrospective serial-section electron microcopy, which is technically challenging and painstakingly slow [for example, see Trachtenberg et al. (2002) and Knott et al. (2006)]. Therefore, crossing the Munc13-1-EYFP KI with other transgenic, $\mathrm{KO}$, or $\mathrm{KI}$ mice, or using it in combination with other methods such as virus-mediated protein expression should result in new experimental models for studying a variety of topics with long-term in vitro and in vivo imaging.

A second apparent disadvantage of our model is the choice of the GFP spectral variant. When we initiated this study, EYFP was the optimal GFP variant available, but our imaging studies demonstrate that it is relatively sensitive to photobleaching (Fig. 7). It is important to note, however, that since collecting the data presented here, we have taken advantage of recent improvements in emission filter technology, which now allow us to obtain images of comparable or even better quality with significantly less (less than one-half) excitation light intensity. Thus, sensitivity to photobleaching may turn out to be less of a problem, particularly when considering recent improvements in sensor sensitivity (e.g., on-chip amplification CCDs). Nevertheless, our mouse model demonstrates the feasibility of the KI approach for studying the molecular dynamics of active zone proteins and the suitability of such mice for studying more general topics concerning synapse formation, maintenance, and elimination.

\section{Molecular dynamics of Munc13-1 at individual active zones}

Several recent studies have used FRAP to examine the exchange dynamics of GFP-tagged synaptic molecules (Okabe et al., 2001; Yao et al., 2003; Bresler et al., 2004; Nakagawa et al., 2004; Sharma et al., 2006; Tsuriel et al., 2006). These studies revealed that synaptic molecules are continuously lost from and reincorporated into synaptic structures, with kinetics described best by multiexponential recovery curves with time constants in the range of minutes to hours. In all of these studies, fusion protein expression was driven by heterologous promoters, which typically lead to excessive expression levels, raising the possibility that exchange kinetics recorded in these studies were exaggerated to the point of physiological irrelevance. In view of a recent study in which the trafficking of endogenous AMPA-type glutamate receptors was reported to be radically different from that previously described for recombinant receptors (Adesnik et al., 2005), such concerns are not unjustified. Interestingly, however, our FRAP experiments indicate that Munc13-1-EYFP is continuously lost from and reincorporated into active zones at rates similar to those previously reported for other synaptic molecules, and that its recovery exhibits multiexponential kinetics as well. This may indicate that exchange dynamics reported to date for presynaptic molecules are in fact physiologically relevant, and thus our data represent an important validation of previous studies.

Our FRAP experiments indicate the presence of two Munc131-EYFP pools: one with an exchange time constant of $\sim 3$ min that represents $\sim 40 \%$ of total synaptic Munc13-1-EYFP, and a second pool, exchanged much more slowly (time constant of $\sim 80 \mathrm{~min}$ ), that represents $\sim 60 \%$ of the total Munc13-1-EYFP 
(Fig. 7). We postulate that the quickly and slowly exchanging pools correspond to the biochemically distinguishable soluble and insoluble Munc13-1 pools, respectively (Fig. 3C). The quickly exchanging Munc13-1-EYFP pool most likely represents proteins whose diffusion is hindered by transient and weak proteinaceous interactions, because its exchange rate is still much slower than expected of free diffusion (Tsuriel et al., 2006). In contrast, the slowly exchanging Munc13-1-EYFP pool may represent Munc13-1-EYFP anchored to the synaptic plasma membrane, the submembranous cytoskeleton, and the active zone protein network via high-affinity proteinaceous interactions (Brose et al., 1995). Because diacylglycerol and phorbol esters are thought to increase Munc13-1 association with the plasma membrane (Betz et al., 1998), it will be interesting to determine whether these agents slow down the recovery kinetics and thereby increase Munc13-1 residence times at active zones.

Given that Munc13-1 and other active zone proteins engage in high-affinity complexes that resist long biochemical purification procedures, even the slow exchange rate $(\tau \sim 80 \mathrm{~min})$ measured for Munc13-1-EYFP is surprisingly rapid. It indicates that the protein network of the CAZ is highly dynamic, with individual components continuously entering and exiting the network. These dynamics may be of significant functional relevance, because similar turnover rates were observed for the Drosophila Munc13 homolog DUNC-13 (Aravamudan and Broadie, 2003; Speese et al., 2003). The rapid turnover or exchange of Munc13like proteins may contribute to the adaptive and plastic properties of neurotransmitter release. The mechanisms that regulate the dynamics of Munc13-1 in vertebrate synapses remain unknown. Given that the inhibition of protein synthesis and of proteasomal protein degradation has only minor effects on steadystate Munc13-1-EYFP fluorescence, these mechanisms are probably not related to the processes occurring at the Drosophila neuromuscular junction, where DUNC-13 turnover involves rapid synthesis and proteasomal degradation (Aravamudan and Broadie, 2003; Speese et al., 2003). They rather represent the loss and reincorporation of proteins that belong to local, relatively stable, and possibly shared pools of Munc13-1 (Tsuriel et al., 2006). Interestingly, the rates of Munc13-1-EYFP loss and incorporation were reduced after long-term blockade of network activity (Fig. 7). This finding raises the possibility that such reductions in exchange dynamics may play important roles in the slow compensatory increases in synaptic efficacy often associated with reduced levels of neuronal activity (homeostatic plasticity). For example, it is possible that a reduction in the dissociation rate of Munc13-1-EYFP from active zone protein complexes results in a new steady state of increased Munc13-1 content at active zones. We predict that the availability of our mouse model and future KI mice expressing other fluorescently tagged synaptic molecules will allow us to explore these and other problems in ways that were not possible before.

\section{References}

Adesnik H, Nicoll RA, England PM (2005) Photoinactivation of native AMPA receptors reveals their real-time trafficking. Neuron 48:977-985.

Aravamudan B, Broadie K (2003) Synaptic Drosophila UNC-13 is regulated by antagonistic G-protein pathways via a proteasome-dependent degradation mechanism. J Neurobiol 54:417-438.

Augustin I, Betz A, Herrmann C, Jo T, Brose N (1999a) Differential expression of two novel Munc13 proteins in rat brain. Biochem J 337:363-371.

Augustin I, Rosenmund C, Südhof TC, Brose N (1999b) Munc13-1 is essential for fusion competence of glutamatergic synaptic vesicles. Nature 400:457-461.

Betz A, Okamoto M, Benseler F, Brose N (1997) Direct interaction of the rat unc-13 homologue Munc13-1 with the $\mathrm{N}$ terminus of syntaxin. J Biol Chem 272:2520-2526.

Betz A, Ashery U, Rickmann M, Augustin I, Neher E, Südhof TC, Rettig J, Brose N (1998) Munc13-1 is a presynaptic phorbol ester receptor that enhances neurotransmitter release. Neuron 21:123-136.

Betz A, Thakur P, Junge HJ, Ashery U, Rhee JS, Scheuss V, Rosenmund C, Rettig J, Brose N (2001) Functional interaction of the active zone proteins Munc13-1 and RIM1 in synaptic vesicle priming. Neuron 30:183-196.

Bresler T, Ramati Y, Zamorano PL, Zhai R, Garner CC, Ziv NE (2001) The dynamics of SAP90/PSD-95 recruitment to new synaptic junctions. Mol Cell Neurosci 18:149-167.

Bresler T, Shapira M, Boeckers T, Dresbach T, Futter M, Garner CC, Rosenblum K, Gundelfinger ED, Ziv NE (2004) Postsynaptic density assembly is fundamentally different from presynaptic active zone assembly. J Neurosci 24:1507-1520.

Brose N, Hofmann K, Hata Y, Südhof TC (1995) Mammalian homologues of Caenorhabditis elegans unc-13 gene define novel family of C2-domain proteins. J Biol Chem 270:25273-25280.

Chalfie M, Tu Y, Euskirchen G, Ward WW, Prasher DC (1994) Green fluorescent protein as a marker for gene expression. Science 263:802-805.

Chi P, Greengard P, Ryan TA (2001) Synapsin dispersion and reclustering during synaptic activity. Nat Neurosci 4:1187-1193.

Darcy KJ, Staras K, Collinson LM, Goda Y (2006) Constitutive sharing of recycling synaptic vesicles between presynaptic boutons. Nat Neurosci 9:315-321.

Dresbach T, Qualmann B, Kessels MM, Garner CC, Gundelfinger ED (2001) The presynaptic cytomatrix of brain synapses. Cell Mol Life Sci 58:94-116.

Dresbach T, Hempelmann A, Spilker C, tom Dieck S, Altrock WD, Zuschratter W, Garner CC, Gundelfinger ED (2003) Functional regions of the presynaptic cytomatrix protein bassoon: significance for synaptic targeting and cytomatrix anchoring. Mol Cell Neurosci 23:279-291.

Dresbach T, Torres V, Wittenmayer N, Altrock WD, Zamorano P, Zuschratter W, Nawrotzki R, Ziv NE, Garner CC, Gundelfinger ED (2006) Assembly of active zone precursor vesicles: obligatory trafficking of presynaptic cytomatrix proteins Bassoon and Piccolo via a trans-Golgi compartment. J Biol Chem 281:6038-6047.

Feng G, Mellor RH, Bernstein M, Keller-Peck C, Nguyen QT, Wallace M, Nerbonne JM, Lichtman JW, Sanes JR (2000) Imaging neuronal subsets in transgenic mice expressing multiple spectral variants of GFP. Neuron 28:41-51.

Gong S, Zheng C, Doughty ML, Losos K, Didkovsky N, Schambra UB, Nowak NJ, Joyner A, Leblanc G, Hatten ME, Heintz N (2003) A gene expression atlas of the central nervous system based on bacterial artificial chromosomes. Nature 425:917-925.

Griffin BA, Adams SR, Tsien RY (2000) Fluorescent labeling of recombinant proteins in living cells with FlAsH. Methods Enzymol 327:565-578.

Inoue A, Okabe S (2003) The dynamic organization of postsynaptic proteins: translocating molecules regulate synaptic function. Curr Opin Neurobiol 13:332-340.

Jones DH, Matus AI (1974) Isolation of synaptic plasma membrane from brain by combined flotation-sedimentation density gradient centrifugation. Biochim Biophys Acta 356:276-287.

Junge HJ, Rhee JS, Jahn O, Varoqueaux F, Spiess J, Waxham MN, Rosenmund C, Brose N (2004) Calmodulin and Munc13 form a $\mathrm{Ca}^{2+}$ sensor/effector complex that controls short-term synaptic plasticity. Cell 118:389-401.

Knott GW, Holtmaat A, Wilbrecht L, Welker E, Svoboda K (2006) Spine growth precedes synapse formation in the adult neocortex in vivo. Nat Neurosci 9:1117-1124.

Kraszewski K, Daniell L, Mundigl O, De Camilli P (1996) Mobility of synaptic vesicles in nerve endings monitored by recovery from photobleaching of synaptic vesicle-associated fluorescence. J Neurosci 16:5905-5913.

Lakso M, Pichel JG, Gorman JR, Sauer B, Okamoto Y, Lee E, Alt FW, Westphal $\mathrm{H}$ (1996) Efficient in vivo manipulation of mouse genomic sequences at the zygote stage. Proc Natl Acad Sci USA 93:5860-5865.

Li Z, Murthy VN (2001) Visualizing postendocytic traffic of synaptic vesicles at hippocampal synapses. Neuron 31:593-605.

Miyawaki A, Sawano A, Kogure T (2003) Lighting up cells: labelling proteins with fluorophores. Nat Cell Biol [Suppl] S1-S7.

Mueller VJ, Wienisch M, Nehring RB, Klingauf J (2004) Monitoring 
clathrin-mediated endocytosis during synaptic activity. J Neurosci 24:2004-2012.

Nakagawa T, Futai K, Lashuel HA, Lo I, Okamoto K, Walz T, Hayashi Y, Sheng M (2004) Quaternary structure, protein dynamics, and synaptic function of SAP97 controlled by L27 domain interactions. Neuron 44:453-467.

Okabe S, Urushido T, Konno D, Okado H, Sobue K (2001) Rapid redistribution of the postsynaptic density protein PSD-Zip45 (Homer 1c) and its differential regulation by NMDA receptors and calcium channels. J Neurosci 21:9561-9571.

Rhee JS, Betz A, Pyott S, Reim K, Varoqueaux F, Augustin I, Hesse D, Südhof TC, Takahashi M, Rosenmund C, Brose N (2002) Beta phorbol esterand diacylglycerol-induced augmentation of transmitter release is mediated by Munc13s and not by PKCs. Cell 108:121-133.

Rosenmund C, Stevens CF (1996) Definition of the readily releasable pool of vesicles at hippocampal synapses. Neuron 16:1197-1207.

Rosenmund C, Sigler A, Augustin I, Reim K, Brose N, Rhee JS (2002) Differential control of vesicle priming and short-term plasticity by Munc13 isoforms. Neuron 33:411-424.

Rosenmund C, Rettig J, Brose N (2003) Molecular mechanisms of active zone function. Curr Opin Neurobiol 13:509-519.

Sankaranarayanan S, Atluri PP, Ryan TA (2003) Actin has a molecular scaffolding, not propulsive, role in presynaptic function. Nat Neurosci 6:127-135.

Shapira M, Zhai RG, Dresbach T, Bresler T, Torres VI, Gundelfinger ED, Ziv NE, Garner CC (2003) Unitary assembly of presynaptic active zones from Piccolo-Bassoon transport vesicles. Neuron 38:237-252.

Sharma K, Fong DK, Craig AM (2006) Postsynaptic protein mobility in dendritic spines: Long-term regulation by synaptic NMDA receptor activation. Mol Cell Neurosci 31:702-712.

Speese SD, Trotta N, Rodesch CK, Aravamudan B, Broadie K (2003) The ubiquitin proteasome system acutely regulates presynaptic protein turnover and synaptic efficacy. Curr Biol 13:899-910.

Star EN, Newton AJ, Murthy VN (2005) Real-time imaging of Rab3a and Rab5a reveals differential roles in presynaptic function. J Physiol (Lond) 15:103-117.

Südhof TC (2004) The synaptic vesicle cycle. Annu Rev Neurosci 27:509-547.

Tamamaki N, Yanagawa Y, Tomioka R, Miyazaki J, Obata K, Kaneko T (2003) Green fluorescent protein expression and colocalization with calretinin, parvalbumin, and somatostatin in the GAD67-GFP knock-in mouse. J Comp Neurol 467:60-79.

Thomas KR, Capecchi MR (1987) Site-directed mutagenesis by gene targeting in mouse embryo-derived stem cells. Cell 51:503-512.

Trachtenberg JT, Chen BE, Knott GW, Feng G, Sanes JR, Welker E, Svoboda $\mathrm{K}$ (2002) Long-term in vivo imaging of experience-dependent synaptic plasticity in adult cortex. Nature 420:788-794.

Tsuriel S, Geva R, Zamorano P, Dresbach T, Boeckers T, Gundelfinger ED, Garner CC, Ziv NE (2006) Local sharing as a predominant determinant of synaptic matrix molecular dynamics. PLoS Biol 4:1572-1587.

Vardinon-Friedman H, Bresler T, Garner CC, Ziv NE (2000) Assembly of new individual excitatory synapses: time course and temporal order of synaptic molecule recruitment. Neuron 27:57-69.

Varoqueaux F, Sigler A, Rhee JS, Brose N, Enk C, Reim K, Rosenmund C (2002) Total arrest of spontaneous and evoked synaptic transmission but normal synaptogenesis in the absence of Munc13-mediated vesicle priming. Proc Natl Acad Sci USA 99:9037-9042.

Yao I, Iida J, Nishimura W, Hata Y (2003) Synaptic localization of SAPAP1, a synaptic membrane-associated protein. Genes Cells 8:121-129.

Zhai RG, Bellen HJ (2004) The architecture of the active zone in the presynaptic nerve terminal. Physiology (Bethesda) 19:262-270.

Zhen M, Jin Y (2004) Presynaptic terminal differentiation: transport and assembly. Curr Opin Neurobiol 14:280-287. 